\title{
La representación del conocimiento \\ en la memoria * *
}

\section{David E. Rumelhart}

University of California at San Diego.

\section{Andrew Ortony}

University of Illinois at Urbana Champaign.

Traducción: Eulalia Rubi

Salvador Tarrat

Muchos artículos de psicología cognitiva o evolutiva no lo son a la vez de psicopedagogía aplicada. Pero en algunos casos, algún trabajo teórico o de investigación ilumina de tal manera nuestro conocimiento de lo que es el niño y de sus procesos, que el educador práctico extrae de él toda una nueva perspectiva y comprensión para su trabajo cotidiano. Véase este ejemplo.

" aThe representation of Knowledge in Memoryo. En A.C. Anderson, R.J. Spiro, W. E. Montague (Eds.). Schooling and the acquisition of knowledge. Hillsdale, New Jersey: Erlbaum, 1977, pp. 99.135., Reproducido con autorización • de esta traducción. Infancia y Aprendizaje, 1982.

** «El articulo que, en un principio, fue presentado a la conferencia por Rumelhart, y discutido por Ortony, ha sido sustituido por este esfuerzo conjunto. De aqui la ausencia de una discusión abierta y formal.») 


\section{INTRODUCCION}

Aunque se origina a partir de los sentidos, el conocimiento no es un registro ciego de estímulos sensoriales. Las personas normales no son grabadoras, ni aparatos de video; sino que, al parecer, procesan y reprocesan la información, imponiendo en ella, y produciendo a partir de ella, un conocimiento con estructura. El sistema de la memoria humana es un amplio almacén de dicho conocimiento, parte de este conocimiento parece tener forma de recuerdos específicos, de sucesos particulares, que hemos esperimentado, y parte de él, tiene la forma de abstracciones más generales, que ya no están ligadas a ningún tiempo, lugar o gente. Una de las tareas de toda teoría so. bre la representación del conocimiento es la de dar una caracteriza: ción de la forma en la que se estructura el pensamiento, de modo que se pueda ir avanzando la respuesta a otras cuestiones importan. tes: ¿Cómo está organizada la memoria, para que se tenga habitual. mente acceso a la información apropiada, cuando ésta se requiera? ¿Qué papel juega el conocimiento ya adquirido en la adquisición del nuevo? ¿De qué modo el estado actual de nuestro conocimiento mo. dula nuestras acciones? En ninguna de las teorías que conocemos, se dan respuestas totalmente satisfactorias a este tipo de preguntas. No obstante, en los cinco o diez últimos años, se han realizado progresos sustanciales encaminados a responderlas. Creemos que es un tributo a estos esfuerzos el que un trabajo sobre la representación del conocimiento pueda incluirse en un volumen como éste.

Los progresos a los cuales nos referimos, pueden ser considerados como el punto focal de una nueva disciplina denominada ciencia cognitiva. Las investigaciones de un número cada vez mayor de gente que trabaja en los campos de la inteligencia artificial, la psico. logía cognitiva, y la lingüística aplicada a problemas referentes a la representación del significado y los aspectos estructurales y de procesamiento del conocimiento, revelan una convergencia sustancial de opiniones respecto a los componentes esenciales de los sistemas de representación del conocimiento.

Recientes trabajos de Bobrow y Norman (1975), Minsky (1975), Norman, Rumelhart y LNR (1975), Rumelhart (1975) Schank y Abelson (1975) y Winograd (1975) confirman esta convergencia. Aunque diferenciándose unos de otros, a veces de forma importante, hay no obstante, un acuerdo respecto a las nociones generales, manifestadas o supuestas por estos autores.

En este trabajo, esbozaremos estas nociones generales, y desarrollaremos algunos de los argumentos a favor de una aproximación general. 
Aunque muchos aspectos de las ideas que desarrollaremos di. fieren de anteriores enfoques, no es nuestro propósito hacer una re. visión crítica de ninguno de ellos, ni tampoco tratar de comparar ex. plícitamente nuestro enfoque con los de los demás. Más bien hemos reunido, lo que consideramos los mejores aspectos de cada uno de los distintos avances y construido lo que nos parece ser la visión compuesta más razonable. Hemos formulado nuestras ideas en el contexto de las Redes Estructurales Activas de Norman, Rumelhart y LNR (1975), en la medida en que los detalles técnicos sean necesa. rios; y sintetizando el trabajo de Rumelhart y Levin (1975), y de Rumelhart (1975).

Aunque no compararemos nuestras consideraciones sobre la representación de conocimiento, que denominaremos con el término de schemata (singular: schema), con las consideraciones de los demás autores, sería apropiado que indicáramos los conceptos que pueden ser asociados a las propuestas de puntos de vista similares. La teoría propuesta por Minsky (1975) está basada en lo que él deno. minaba estructuras (frames) Winograd (1975), Charniak (1975) y otros estudiosos de la inteligencia artificial han seguido en gran medida la formulación de Minsky. Bobrow y Norman (1975) hanutilizado el tér. mino esquema ((sscheman)) de modo parecido al utilizado en nuestro trabajo. Norman, Rumelhart y LNR (1975) han utilizado el término definición ((definition)) donde nosotros utilizamos el término esque ma ((schema)). Schank y Abelson (1975), Schank et al (1975) utilizan guión ((script») para referirse a un tipo de esquemas y el término plan ((cplan)) para referirse a un tipo algo más abstracto de esque mas. Rumelhart (1975) también utiliza el término esquema ((sschema»)) para referirse a un grupo de (esquemas), abstractos semejantes a los "planss) de Schank y Abelson.

\section{LOS ESQUEMAS}

Un tema central en un trabajo del tipo al que hemos hecho re ferencia, es postular las estructuras interactuantes del conocimiento que, como ya hemos indicado, denominaremos esquemas. El término aparece en la psicología moderna a través de los escritos de Bar. tlett (1932), lo cual es reconocido por la mayoría de los estudiosos. No obstante es interesante señalar, que en su Crítica de la Razón Pura, Kant (1787) utiliza una noción de esquemas, que en muchos aspectos resulta más similar a la nuestra que la del propio Bartlett '.

Los esquemas son estructuras de datos para representar los con. ceptos genéricos almacenados en la memoria. Los esquemas existen para conceptos generalizados subyacentes a los objetos, situaciones, 
sucesos, secuencias de sucesos, acciones y secuencias de acciones. Los Esquemas no son atómicos. Un esquema contiene, como parte de su especificación, la red de interrelaciones que se cree que general. mente existe entre los constituyentes del concepto en cuestión.

Los esquemas, en cierto sentido, representan estereotipos de estos conceptos. Aunque la comparación resulte simplista, puede ser útil pensar que un esquema es análogo a una obra de teatro, la es. tructura interna del esquema correspondería al guión de la obra. Un esquema está relacionado con un caso particular del concepto que representa, del mismo modo que una obra está relacionada con una representación particular de la misma.

En nuestra opinión, hay cuatro características esenciales de los esquemas, que se combinan para poder representar el conocimiento en la memoria. Estas son: (1) los esquemas tienen variables; (2) los esquemas pueden encajarse uno dentro de otro; (3) los esquemas repre. sentan conceptos genéricos, que tomados conjuntamente varían en sus niveles de abstracción; (4) los esquemas representan el conocimiento más que definiciones. En éste apartado discutiremos éstos cuatro rasgos uno a uno, ilustrando con ejemplos diferentes aspec. tos de cada uno. El epígrafe dedicado a las variables resultará largo porque en él se introducen por primera vez muchos conceptos.

\section{Las variables en los esquemas}

Dèl mismo modó que una obra tiene distintos papeles, que pueden estar representados por diferentes actores en diferentes actuaciones, también los esquemas tienen variables, que pueden estar asociadas con, o limitadas por, diferentes aspectos de nuestro medio en diferentes ocasiones. En el contexto de la lingüística estas variables han sido denominadas (casos») (cases) siguiendo la gramática de casos de Filmore (1968).

Por ejemplo, podemos tomar un esquema para (DAR), que tendría tres variables, el dador, el objeto dado y el receptor. En distintas ocasiones las variables del esquema DAR toman valores diferentes. Estos valores vienen determinados por aspectos del entorno, es decir, por factores situacionales y contextuales, y por el estímulo que ha de comprenderse. Así pues, el entorno proporciona referencias para las conceptualizaciones mentales, que se asocian con las variables del esquema. Pero, aunque las variables pueden verse limitadas por diferentes aspectos ambientales en distintas ocasiones, las relaciones dentro del esquema DAR permanecen, sin embargo, constantes. Particularmente, el dador causará, en cierto modo, que el receptor reciba el objeto dado. Normalmente esto sería cierto sin 
tener en consideración la identidad del dador o del receptor, o la naturaleza del objeto dado. Y decimos (normalmente), porque en ciertos casos, que discutiremos más adelante, pueden encontrarse excepciones a estas generalizaciones.

La figura 1 ilustra la representación de la Red Estructural Activa del esquema DAR, anteriormente discutido. (Para una discusión detallada de las Redes Estructurales Activas véase Norman, Rumelhart, LNR [1975D. El término de la casilla superior, no inscrito en un círculo, representa el nombre del esquema. La flecha denominada (ces cuandom señala la estructura interna del esquema. Las variables $\mathrm{X}, \mathrm{Y}$ y $\mathrm{Z}$ vienen señaladas por vectores denominados (DADOR), (RECEPTOR» y "OBJETO DADO» respectivamente. Los términos inscritos en un círculo representan sub-esquemas. Las flechas a partir del sub-esquema, muestran cómo las variables del esquema se relacionan con las del sub-esquema. Asi pues, el DADOR del esquema DAR es el agente del subesquema CAUSA. Obsérvese, que el subesquema OBTENER juega el papel de "suceso causado" por el esque. ma CAUSA. Como veremos, los schemas reales son algo más complejos. La representación que se hace aquí es tan sólo a título de ilus. tración.

Del mismo modo que tan sólo ciertas características de los actores están especificadas por el autor (ejemplo: sexo, edad, apariencia), asi también un esquema contiene, como parte de su espicificación, información acerca de los (tipos) de objetos que pueden relacionarse con las diversas variables del esquema. Así, en nuestro ejemplo anterior DAR podríamos, por ejemplo, incorporar al esquema espe. cificaciones en el sentido de que el (dador) deba ser capaz de una acción voluntaria (ćanimada?). Dichas limitaciones en los valores que pueden tomar las variables, tienen dos funciones importantes: (1) nos dice qué tipo de objetos podrían realmente relacionarse con cada variable y (2) cuando la información es insuficiente, pueden permitir que se hagan conjeturas sobre, por lo menos, alguna de las variables.

El siguiente ejemplo pretende clarificar el proceso por el cual se produce la relación entre variables. Supongamos un esquema del concepto de alguien rompiendo algo. Podemos imaginar por lo menos, tres variables asociadas con el esquema: el que rompe, el objeto y el método por el cual es roto el objeto. Podríamos esperar que el que rompe fuera una fuerza agente, que el objeto fuera rígido o frágil y, que el método fuera una acción, que el que rompe es capaz de realizar, y suficiente para romper el objeto en cuestión. La figura 2 ilustra cómo podría representarse tal esquema en forma de red es. tructural activa. 


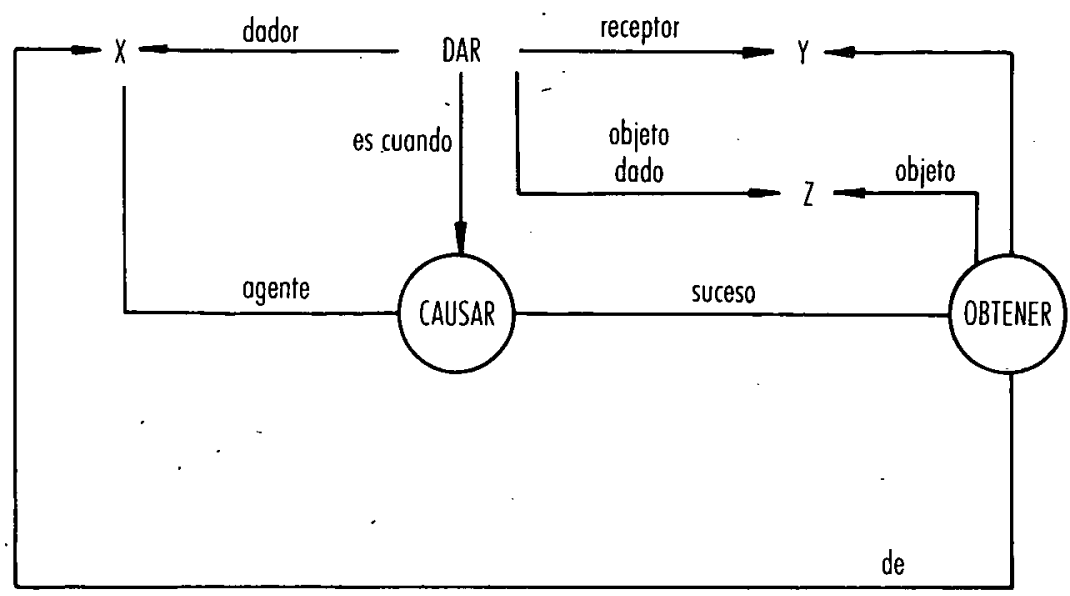

FIGURA 1: Representación diagramática del esquema DAR

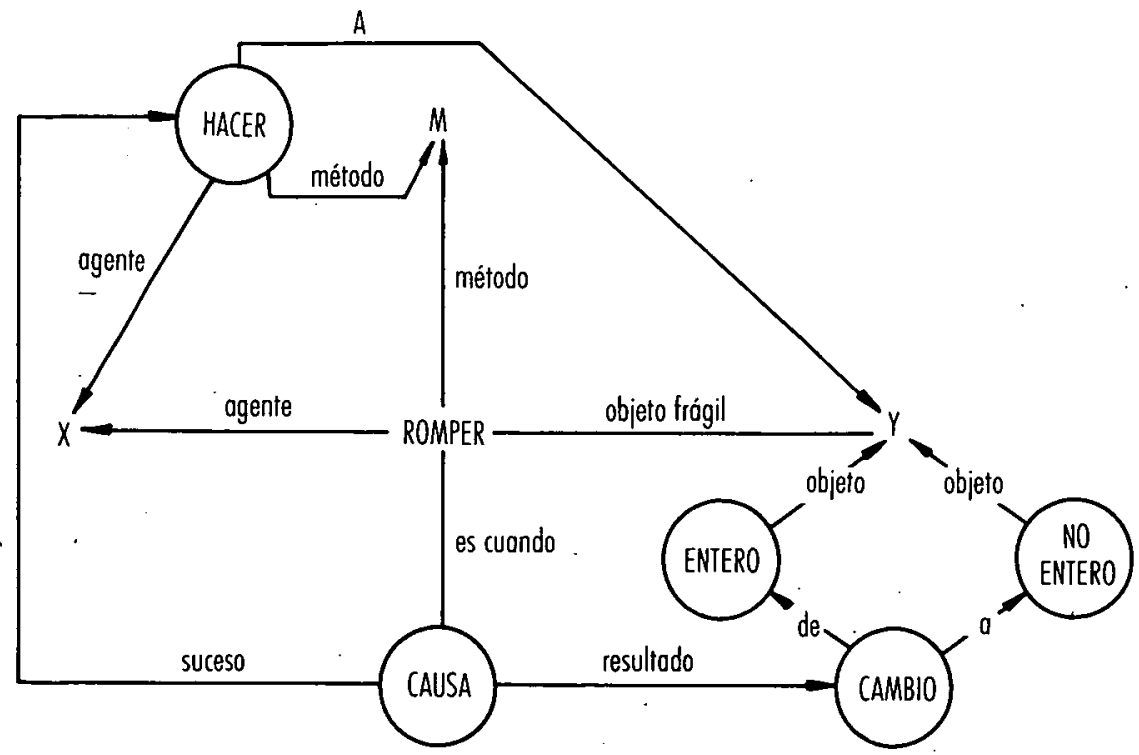

FIGURA 2: Representación diagramática del esquema ROMPER 
Consideremos ahora las siguientes frases:

(1) Juan rompió la ventana

(2) La pelota rompió la ventana

(3) Juan rompió el globo

En cada caso, utilizando nuestra analogía de la obra de teatro, podemos decir que cada frase describe una representación de la obra ROMPER. Sin embargo, obtenemos imágenes bastante diferenciadas de las relaciones entre los sujetos y objetos de estas frases. Es decir, a pesar de las similitudes superficiales entre las frases, los papeles son asignados de manera que producen representaciones de la obra muy diferentes.

Compárense primero los frases (1) y (2). Supongamos quizás que, puesto que la palabra romper aparece en la frase, nos hayamos visto inducidos a considerar nuestro esquema ROMPER como una posible explicación para estas frases. Ahora debemos asociar de algún modo los otros conceptos a los que se ha hecho referencia en las frases con las variables del esquema. Las limitaciones de las variables pueden ayudarnos a hacerlo. En ambos casos, la (ventana" será probablemente tomada como objeto y asociada con la variable Y (en la figura). La ventana cumple claramente el criterio de ser un objeto rígido. En la frase (1), Juan encajará facilmente como (rompedorm, $\mathrm{X}$, ya que Juan es probablemente el nombre de una persona $\mathrm{y}$ ya que las personas son estereotipos de fuerzas agentes. No obstante, en la frase (2) la (pelota) no será fácilmente relacionada con la variable $\mathrm{X}$, porque no se considera fácilmente una fuerza agente. Así, hemos de hacer una hipótesis sobre la identidad de la variable X. Sabemos que $X$ puede ir ligada a una persona no especificada $O$ cal. guien), pero, ¿qué ocurre entonces con la (pelota)? Hay otra variable en el esquema romper del que podemos sevirnos para dar cuen. ta de (pelotan, a saber, el método.

Así, tenemos a calguien que ha causado la rotura de la ventana con la pelota». Pero ¿qué acción llevó a cabo ese (alguien»? No tene. mos información directa, $y$ de nuevo debemos establecer una hipótesis plausible. Sabemos por las limitaciones de la variable que, cualquiera que ésta sea, debe haber sido suficiente para causar la ro. tura de la ventana. Podríamos dejarlo así, o revisar el esquema pelota, o podríamos buscar en nuestra memoria otros casos en que objetos como pelotas rompen objetos como ventanas, y ver qué tipo de actividades se ven implicadas en ellos. Si hubiéramos de llevar ade. lante esta inferencia probablemente determinaríamos que la pelota (quizás una de béisbol) fue impulsada de algún modo a través de la ventana. De este modo, aunque el método concreto no esté establecido en parte alguna,las limitaciones de la variable dentro del es- 
quema han permitido la asignación de un valor probable a una de las variables. La asignación de valores inferidos a las variables, la denominamos asignación de valores ausentes (Minsky 1975). Obsérve. se no obstante, que no es preciso decidir estos valores ausentes con idependencia de los valores de las demás variables. En lugar de ello, se deciden contingentemente, asignando el válor a una variable par. ticular (como en el caso del método en nuestro ejemplo) en función del valor de otras variables (como en el caso del objeto en nuestro ejemplo).

Ahora comparemos la frase (1) con la frase (3). La unión de las variables $\mathrm{X}$ e $\mathrm{Y}$ (el que rompe y el objeto respectivamente) no presenta problemas. En ambos casos Juan es el que rompe. En un caso el objeto es la (ventana) y en el otro (el globo»). No obstante, obten. dremos probablemente imágenes bastante distintas del método utilizado en estos dos casos. Esta diferencia es presumiblemente el resultado del conocimiento que tenemos acerca del tipo de actividades que son suficientes para romper un objeto de la resistencia de la ventana, en oposición al tipo de actividades, que son suficientes para romper algo de la tirantez de un globo. Esta información podría ya haber sido extraida y directamente asociada con el esquema ROMPER, o podría ser descubierta consultando nuestros recuerdos sobre diversos ejemplos de casos en que se han roto ventanas y globos.

En resumen, los esquemas poseen variables a las que van asociadas limitaciones a las variables. Estas limitaciones cumplen dos funciones. Primera, nos ayudan a asignar valores a las variables, es. pecificando los tipos de cosas que pueden cubrir los diferentes papeles en el esquema. Segunda, cuando dicha asignación no puede hacerse simplemente en base al estímulo actual, o recurriendo a la memoria, las limitaciones puedén ayudar a generar asignaciones au. sentes. Una vez realizada la asignación de variables, ya sea a partir del entorno, de la memoria, o mediante ausencia, se dice que el esquema ha sido activado, puesto en marcha. De nuestra discusión sobre la comprensión se derivará que la puesta en marcha del esquema es tan sólo el primer paso hacia la comprensión. A partir de aquí, el proceso de activación de subesquemas o de esquemas domi. nantes, puede continuar, modificando quizás las asignaciones originales de variables. Este proceso de activación de esquemas relacio. nados, esta emparentado con la noción de Craik y Lockhart (1972) de niveles de procesamiento.

Antes de dejar nuestra discusión sobre las variables y las limitaciones de las variables, deberíamos de mencionar que las limitaciones de las variables no suelen ser absolutas. Es raro el caso en que una variable no pueda nunca aceptar un valor de un cierto tipo. Más 
bien resulta práctico considerar las limitaciones de variables, como representantes de distribuciones de valores posibles. Una variable concreta puede tomar un valor cualquiera de una gama de valores posibles, pero algunos valores son más típicos que otros. La evidencia empírica del criterio según el cual la información distribucional tiene que ser representada, puede encontrarse en Walker (1975), que descubrió que el entendimiento de valores de atributos de objetos físicos, era más rápido cuando estos valores se estimaban, bien como extremos o como típicos. La primacía de los valores prototipo es defendida por ejemplo por Rosch (1973). Por ejemplo (dar) tiende a requerir que el (dador) sea una persona, pero por supuesto los gobiernos y otras instituciones pueden dar en el mismo sentido que una persona dichos valores, sin embargo, son menos típicos. Ante una elección, la limitación de variables preferirá valores más próximos a la (media) de la distribución, pero aceptará valores que se aparten de ésta si no se puede hacer otra interpretación.

De hecho, deberíamos considerar que el conjunto de limitaciones de variables para un determinado esquema forma una distribución multivariada con correlaciones entre las distintas variables.Así, como se ilustra en nuestro ejemplo ROMPER, al decidir una variable aún no especificada preferimos valores próximos a la (median para esa variable, condicionándolos a los valores de las variables ya de. cididas. Halff, Ortony y Anderson (en prensa) describen datos que demuestran precisamente este tipo de sensibilidad al contexto, con pares de nombre-adjetivo. El grado en que un esquema concreto ajusta con un estado concreto dependerá en líneas generales de la probabilidad de que esa configuración concreta de variables se corresponda con ese esquema concreto. Se puede considerar a algu. nos de los descubrimientos experimentales de la comprensión del lenguaje como un leve apoyo a esta última afirmación (Anderson y Ortony 1975, Barday, Brandsford, Franks, McCarrell y Nitsch 1974, Johnson, Brandsford y Solomon. 1973)

\section{Encaje de esquemas}

Del mismo modo que las entradas para los elementos lexicales en un diccionario consisten en otros elementos lexicales, la es. tructura de un esquema viene dada en términos de relaciones entre otros esquemas. Como veremos, en algunos casos, los esquemas pueden incluso encajarse dentro de sí mismos, es decir, algunos es. quemas son estructuras recursivas.

En este epígrafe, nos limitaremos a tratar los esquemas más simples como los de la figura 1 y 2 en que los términos inscritos en 


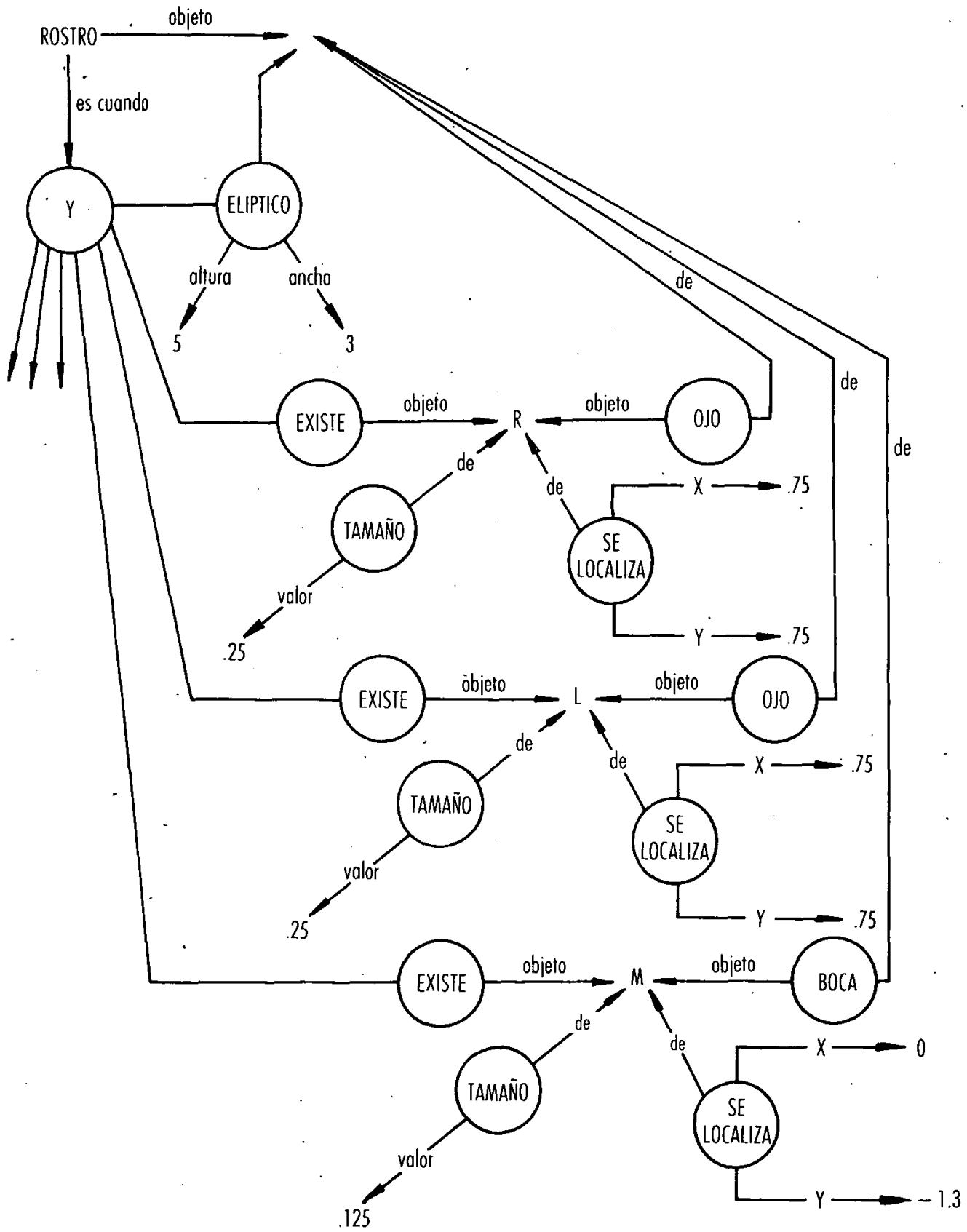

FIGURA 3A

Representación diagramática de a) parte de un esquema ROSTRO y b) parte de un esquema OJO. Los valores indicados no deberían de ser considerados como que representen distancias en términos de un sistema métrico. Más bien representan aproximaciones numéricas referentes a tamaños y distancias relativas. 


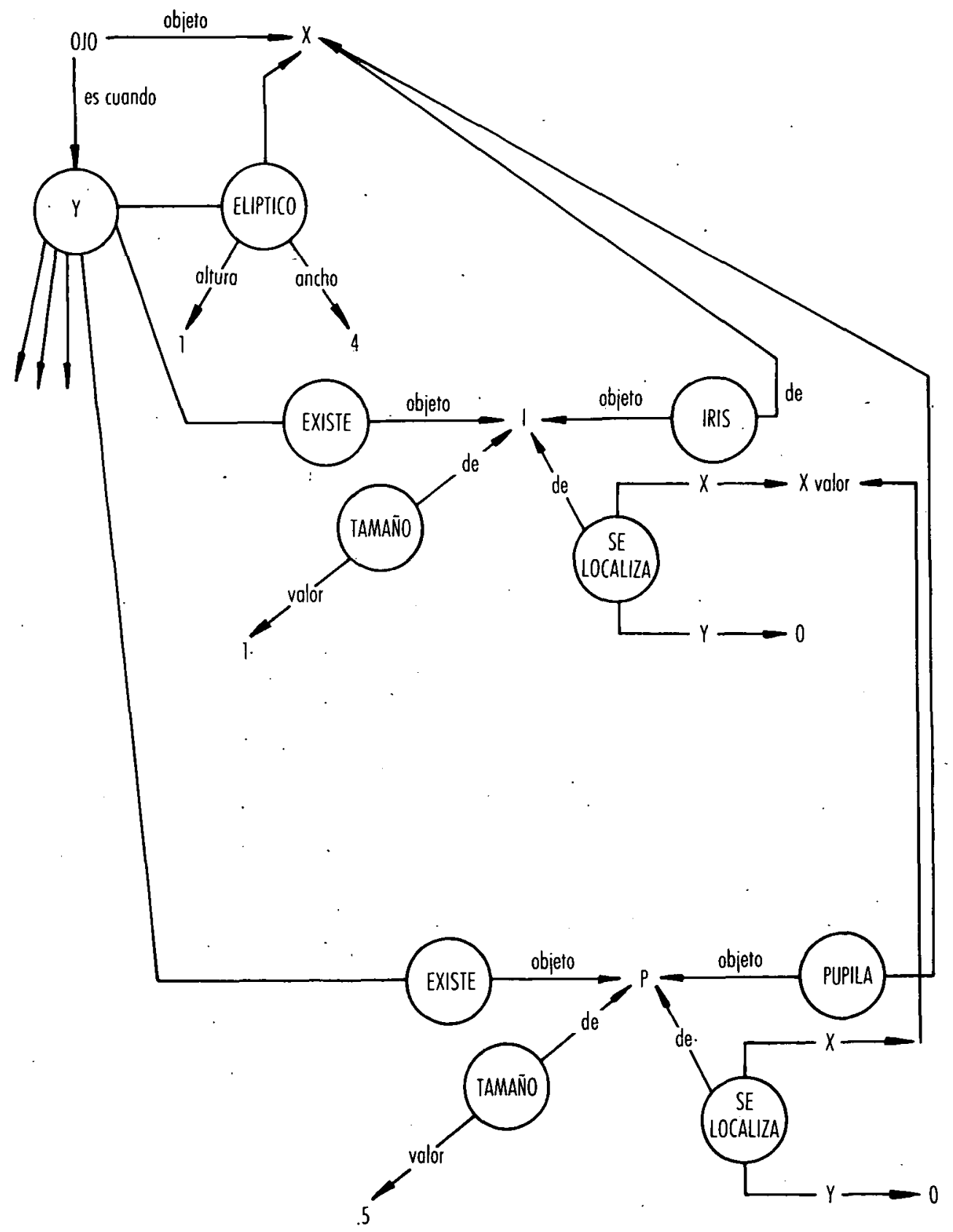


un círculo, son los nombres de los esquemas encajados, que denominamos subesquemas. Estos están representados dentro de los esque. ma en que aparecen, esquemas dominantes, por medio de nombres o etiquetas, y no por sus estructuras completas. Resulta claro que si representáramos las propias estructuras se daría la absurda consecuencia de que cada esquema en la memoria contendría el conocimiento que se encuentra en la mayor parte, por no dec̈ir en todos, los demás esquemas en la memoria. Esta multiplicación explosiva de representaciones de conocimiento se detiene simplemente incor. porando referencias que únicamente identifican a los subesquemas puesto que dichos nombres no incorporan otros nombres.

Considérese el esquema ROSTRO ilustrado en la figura 3A, basado en un modelo descrito por Palmer (1975). En él, se encuentran referencias a esquemas de ojos, oídos, boca, etc. La esencia del esquema ROSTRO es la especificación de las partes que lo constituyen normalmente, de los subesquemas y de la especificación de las rela. ciones que normalmente mantienen entre ellos. Obsérvese que el esquema para OJO en la figura 3B, tiene como subesquema pupila, iris, párpado, etc, ninguno de los cuales aparece en el esquema ros. tro.

La organización global resultante es jerárquica, no solamente en el sentido de una jerarquía de conceptos relacionados por la in. clusión de clases (como en Collins y Quilliam, 1969), sino también de un modo más general. Esta organización parece llevar a una regre. sión infinita, en la cual cada esquema está caracterizado en términos de constituyentes de nivel inferior o subesquemas. Probablemente, la dependencia que los esquemas mantienen respecto a los subesquemas de nivel inferior debe al final detenerse, es decir, algunos esquemas deben ser atómicos en el sentido de que no están caracte. rizados por referencias a cualquier otro esquema constituyente. Es. tos esquemas atómicos corresponden a lo que Norman, Rumelhart y LNR (1975) denominan primitivos.

Muchos de ellos, probablemente representan procedimientos senso-motores básicos, mientras que otros pueden representar com. ponentes conceptuales no analizables de conocimiento humano, como el de la (conexión causal), que como Hume señaló hace 200 años, no puede extraerse sólo de la experiencia. Así pues, todo nuestro sistema de conocimiento dependería en el fondo de un grupo de esquemas atómicos.

La propiedad de encaje que tienen los esquemas proporciona. un número importante de ventajas, la principal de ellas, es que una situación o un objeto puede ser comprendido en términos de sus constituyentes principales sin que sean necesarias referencias a la 
estructura interna de los propios constituyentes. Pero al mismo tiempo se puede conseguir una comprensión (más profunda) si se hace referencia a la estructura interna de estos constituyentes. Así por ejemplo, un rostro puede ser imaginado como una cierta configuración de ojos, nariz, boca, etc y no como una configuración enormemente compleja de esos atributos perceptuales elementales de los que depende, en última instancia, la percepción del rostro. De un modo similar la éstructura de un esquema nos permite distinguir entre las relaciones que existen entre los subesquemas y las que existen entre los constituyentes en cualquiera de esos subesquemas. Así, supóngase que se observa un suceso en el que dos personas ha. blan sentadas una al lado de la otra. Ya que se utiliza el esquema PERSONA, los pies de una persona se ven más ligados a la cabeza de esa persona que a los pies de la segunda persona. El suceso se percibiria de este modo aunque los pies de ambos estuvieran de hecho fí. sicamente más próximos que los pies de cualquiera de las dos personas respecto a la propia cabeza de la persona. Dicho de otro modo, podemos decir, que nuestro conocimiento de la gente nos guía para percibir a la gente como gente e inhibe la agrupación estúpida de objetos en base a similitud o proximidad. Los objetos se agrupan, pero sólo en base a los esquemas que se utilizan en su interpretación.

Una segunda ventaja de este encaje, relacionada con la prime. ra, es la economía representacional de variables. En el epígrafe anterior discutíamos un esquema de DAR. Uno de los subesquemas que aparecía en él estaba presente en cuanto uno de los múltiples sentidos de (causa). El sentido concreto en cuestión de (causa), pue. de ser traducido aproximadamenre por (hacer y (de ahi) causar). Habrá un esquema para este sentido de causa que incluirá, peto no será idéntico al, esquema atómico de causa. El esquema HACER se acerca más a algún esquema de acción primitivo, que el esquema DAR o el esquema ROMPER, en los cuales la referencia es directa. En consecuencia, será accesible de una u otra manera, en casi todos los esquemas que representen verbos de acción de nivel superior ((nivel superior), significa aquí alejamiento de los primitivos). Así pues, algunas veces, como en el caso del esquema DAR, el esquema HACER será accesible a partir del esquema que soporta el sentido apropiado "de causa" y otras veces como en el esquema ROMPER, HACER no pasará de ser un subesquema. Pero en todos los casos y asociados a un esquema de nivel inferior, del tipo de HACER, habrá varias variables subsidiarias, para responder a preguntas del tipo ¿Cúando? ¿Dónde? ¿Porqué? y ¿Cómo? De esta forma, en lugar de requerirse variables para los aspectos de la acción tales como tiem. po, lugar, razón, y modo, que deberían estar asociadas a cada una de los esquemas de nivel superior que representen un tipo de acción, la 
articulación de estas variables puede, a menudo, realizarse a nivel del esquema HACER. Puede, o no puede; que sea una observación interesante el hecho de que cuando se nos dice que Juan rompió una ventana solemos preguntar, cúando (dónde, porqué y cómo) lo hizo, casi al mismo tiempo que preguntamos sobre el hecho de que la rompiera. Tal vez nuestro lenguaje ordinario refleja a veces el papel que juegan estas estructuras subyacentes, no obstante no debería de exagerarse el significado de dichas observaciones.

\section{Los esquemas y los niveles de abstración}

La tercera característica principal de los esquemas aparece claramente al final del apartado anterior. Hay esquemas en todos los niveles de abstracción. Merece la pena que hagamos mención es. pecial de esta característica puesto que es este aspecto el que distancia de forma más completa nuestra posición de intentos anteriores de representar la memoria semántica. En general, los trabajos pre. cedentes (véase Anderson y Bower 1973; Kintsch 1972, Quilliam 1972, Rumelhart, Lindsay y Norman 1972; Schank 1972) se han concentrado en la representación de la estructura interna de elementos léxicos, a lo sumo. Tan sólo muy recientemente se han intentado re. presentar conceptualizaciones de niveles más abstractos, como secuencias de acción o tramas de historias. El trabajo que se ha realizado en este área, está en sus incios (véase Charniak 1972; Rumelhart 1975; Schank y Abelson 1975). La necesidad de teorías de representación del conocimiento, lo suficientemente convincentes como para poder manejar conceptualizaciones de nivel superior, se hace más obvia cuando se considera lo esenciales que parecen ser para dar cuenta de nuestra capacidad para orgaizar, resumir y recuperar información sobre secuencias relacionadas de hechos. En particular, si incluimos es este contexto la lectura de un discurso trabado, como de hecho deberíamos hacer, pareceria que dichas actividades constituyen el grueso del volumen de procesamiento de información que lleva a cabo la gente, tanto dentro como fuera del marco de la edu. cación formal. Es realmente raro, que la comprensión sea completamente necesaria fuera de un contexto, y cuando lo es, parece que tengamos una extraña habilidad para construir un contexto dentro del cual, o tal vez, por medio del cual, interpretar el input.

Así pues, consideremos al sistema de la memoria humana como un contenedor de innumerables paquetes de información donde, cada paquete se relaciona con otros paquetes que normal. mente forman sus constituyentes. Dichos paquetes representan el conocimiento en todos los niveles de abstracción, que oscila desde los elementos perceptuales básicos, como-la configuración de las lí- 
neas que forman un cuadrado, a los niveles conceptuales abstractos que nos permiten dar resúmenes convincentes de secuencias de su. cesos, que tienen lugar a lo largo de períodos considerables de tiem. po. No vemos gran discontinuidad entre percepción y comprensión. Percepción es la comprensión del estímulo sensorial. Tampoco vemos demasiada discontinuidad entre los planes y las acciones. Tal vez pueda considerarse simplemente a las acciones como planes ejemplificados con valores motores, los cuales a su vez pueden ser, $o$ bien esquemas de acción, como el nadar o bien acciones primitivas como las necesarias para nadar. De hecho, el uso de los esquemas de acción sin referencia a las estructuras internas de sus constituyen. tes puede ser considerado en la ejecución (performance) como una de esas ejecucione (automáticas), que, como nos recuerda Polanyi $(1958,1966)$, se echan a perder, si el que las realiza trata de prestar atención a las acciones constituyentes.

\section{Los esquemas representan el conocimiento}

En lo tratado hasta ahora, nos hemos referido frecuentemente al hecho de que los esquemas representan los constituyentes e inte. rrelaciones que se encuentran normalmente. En el apartado en que se trataba el encaje de esquemas observabamos, por ejemplo, que el esquema ROSTRO da.una especificación de las partes constituyentes (normales) y de las realaciones que (normalmente mantienen entre ellas). También se sugirió, en el apartado de variables que las limitaciones de las variables se consideran más como distribuciones que como límites inviolables. Esta noción parece concordar bien con recientes investigaciones psicológicas, al igual que con los análisis lingüisticos de Labov (1973) y Lakoff (1972).

Si las tres características de los esquemas que hemos tratado hasta ahora fueran las únicas, los esquemas se parecerian más a las entradas de un diccionario que a lo que nosotros tratamos de dar a entender. Seguramente, el hecho de que los esquemas pueden dar. se en todos los niveles de abstracción no excluye que muchos de ellos puedan presentarse como entradas en un diccionario, no obs. tante hay por lo menos dos razones adicionales por las cuales debería de enfatizarse el hecho de que los esquemas no son lo mismo que las entradas en diccionario. En primer lugar, los esquemas re. presentan un conocimiento de carácter más enciclopédico que definitorio, e incluso cuando se representan características (esenciales), lo son en la mayoría de los casos, como características que corres. ponden, típica o normalmente. En segundo lugar, mientras que los diccionarios tratan de proveer registros de isignificados de palabras) los esquemas representan conocimiento asociado a conceptos. 
En consecuencia, no son entidades lingüísticas, sino representaciones simbólicas de conocimiento abstractas, que expresamos y descri. bimos lingüisticamente y que pueden ser utilizados para compren. der el lenguaje, pero que no son lingüísticas en sí mismas.

La característica de la flexibilidad de las limitaciones de la variable es un rasgo muy importante de los esquemas y nos proporcio. na una manera de entender una de las diferencias entre definicio. nes y conocimiento.

No nos resulta imposible comprender la historia de Ulises y el Cíclope cuando descubrimos que el Cíclope es un gigante de un ojo, ni tampoco negamos que Cíclope tenga un rostro aun teniendo un solo ojo. Es una cuestión empirica cuándo y hasta qué punto, las características normales pueden distorsionarse antes de que el esque. ma en cuestión deje de dar una explicación adecuada. El que dichas distorsiones y desviaciones de lo típico se producen es indiscutible $y$, al representar lo que es normalmente cierto, y no lo que es necesa. riamente cierto, los esquemas tienen la capacidad de tolerar dichas desviaciones, y no fracasan a causa de las contradicciones lógicas entre las limitaciones de la variable y los valores asignados probados. El conocimiento tiene que estar estructurado de tal forma que per. mita que los animales muertos continúen siendo animales y que ros. tros con un ojo sigan siendo rostros. Es precisamente por este tipo de razones por lo que las teorías sobre rasgos semánticos, en la medida en que necesitan rasgos definidos para los conceptos, nos parecen inadecuadas (véase Rips Shoben y Smith 1973). Los esquemas intentan representar el conocimiento de un modo flexible reflejando la tolerancia humana a la veguedad, imprecisión y quasi-inconsistencia.

\section{LAS FUNCIONES DE LOS ESQUEMAS}

La caracterización de los esquemas ofrecida hasta ahora los ha presentado como los cimientos básicos del sistema de procesamien. to de información humano. En ete epígrafe nos proponemos profundizar en algunas de las formas en que los esquemas realizan este cometido. Los trataremos su papel primario de comprensión, en la que creemos es el mecanismo central. Además trataremos su función en la creación de registros de experiencia y de recuerdos, como vehículos para el razonamiento en inferencias, y su función en la re. presentación y organización de estructuras de acción.

\section{Comprensión}

Los esquemas son las unidades clave del proceso de compren. sión. Dentro del contexto general que aqui se ha presentado se pue- 
de considerar que la comprensión consiste en seleccionar esquemas y uniones de variables que (expliquen el material) a comprender y luego verificar que estos esquemas realmente (lo explican). Se dice que un esquema (rexplica) una situación, siempre que esa situación puede ser interpretada como un ejemplo del concepto que repre. senta el esquema. Así pues, la mayor parte de lo que se procesa en un sistema basado en esquemas está dirigido a descubrir esos esquemas que explican mejor la totalidad de la información entrante. Cuando se encuentra un grupo de esquemas que al parecer explica suficientemente la información, se dice que la persona ha compren. dido la situación. Bajo esta perspectiva cuando una persona utiliza un esquema para comprender alguno de los aspectos de la situación, el esquema constituye un tipo de teoría sobre esos aspectos. Así, en general puede considerarse al proceso de comprensión como al proceso que utiliza un científico para probar una teoría: se buscan evidencias que tiendan a confirmarla o a rechazarla. Cuando descubrimos una teoría que, para nuestra satisfacción, justifica las observaciones realizadas, sentimos que comprendemos el fenómeno en cuestión.

Uno de los aspectos más importantes de las teorías, compartido por los esquemas, es el papel de la predicción. No es necesario ha. ber realizado todos los experimentos para poder predecir de forma confiada el resultado de muchos esperimentos propuestos، Así por ejemplo, los astrónomos, confiando en sus teorías, pudieron predecir la existencia y localización de Plutón antes de poder observarlo. De modo similar, un esquema nos permite predecir aspectos del estí. mulo que no han sido (y quizás nunca serán) observados. Por ejem. plo, una vez que se ha determinado satisfactoriamente que cierto objeto es una lámpara eléctrica, se tiende a suponer que tiene un interruptor aunque no haya sido observado. De modo similar, al decir que alguien fue al cine se supone normalmente que la persona o el compañero fue a la taquilla y compró una entrada antes de ver la película. Hacemos estas suposiciones porque los esquemas que utilizamos en la comprensión de las escenas en cuestión o de sus descripciones lingüísticas, nos predicen que esos aspectos existen muy probablemente, ya que poseen estas variables. Efectivamente, a me. nudo es posible llevar a cabo el experimento buscando el interrup. tor o preguntando acerca de la compra de la entrada del cine. De hecho, lo hacemos raramente pues, en primer lugar, tenemos ya suficiente confianza en que el esquema predecirá correctamente los resultados de dichos (experimentos» y, en segundo lugar, los aspec. tos de una situación que de esa manera relegamos a suposición, no son generalmente demasiado importantes. Ciertos ambientes, como los tribunales, pueden resultar interesantes, pues muy a menudo no se ven afectados por ninguna de las razones anteriores. 
A fin de introducir una discusión más detallada, trataremos ahora una de las objeciones que podrían presentarse contra las teo. rías del tipo que aquí se proponen. Si la comprensión se consigue utilizando un esquema o un grupo de esquemas para explicar el estí. mulo, ćcómo puede evitarse la absurda conclusión de que existe un esquema para cada estímulo concebible?. La primera respuesta a esta objeción es aceptar, como se hace y se debe, que no hay esque. mas específicos disponibles para cada situación que pueda presen. tarse. No obstante, es igualmente cierto que no podríamos entender cada situación que pudiera presentarse; de hecho, en la realidad no siempre entendemos todas las situaciones que se nos presentan. Normalmente conseguimos por lo menos una comprensión parcial, es decir, si no podemos encontrar un esquema único que justifique totalmente una situación particular, podemos encontrar esquemas para justificar aspe̊ctos particulares de ella. Entonces, el problema es que no podemos encontrar un esquema único que justifique satis. factoriamente y por entero la situación.

La primera respuesta, sin embargo, parece mantener imbatida la objeción, pues no negamos que muy a menudo podemos entender situaciones para las cuales el postulado de un esquema especifi. co para su comprensión sería gratuito. Así, se requiere una segunda respuesta: las nuevas situaciones pueden ser, generalmente, manejadas utilizando no sólo esquemas específicos, sino también esquemas de nivel superior de abstracción, como trataremos de ilustrar en el siguiente ejemplo:

4a María oyó llegar al heladero.

$4 \mathrm{~b}$ (Ella) recordó su dinero de bolsillo.

4 c (Ella) se precipitó dentro de la casa.

Estas tres frases constituyen juntas un retazo de historia al que la mayor parte de nosotros puede fácilmente dar una buena interpretación. Probablemente, esta interpretación es más o menos que Ma. ría oyó llegar al heladero y quería comprar un helado. Comprar un helado cuesta dinero, luego tenía que pensar en una forma rápida de obtenerlo. Recordó algún dinero que aun no había gastado, probablemente estabx dentro de la casa. Así pues, María se apresu. ró a entrar en casa para intentar coger el dinero mientras llegaba el heladero.

Una interpretación de las frases $4 \mathrm{a}$ a $4 \mathrm{c}$ del tipo que se ha dado es una interpretación de lenguaje ordinario, pero, cंcomo se consigue utilizando esquemas?. Está claro que no tenemos un esquema detallado como en el caso del esquema DAR o el esquema ROSTRO para justificar casos de (oir llegar al heladerom. Sin embargo, probablemente tenemos un esquema algo abstracto de (resolución de 
problema» que unido a un número de esquemas menos abstractos explicará las entradas lingüísticas ${ }^{2}$. Supongamos que nuestro esque. ma de resolución de problemas tiene la siguiente estructura:

Esquema de resolución de problemas (persona $\mathrm{P}$, suceso $\mathrm{S}$, meta $\mathrm{M}$ ).

1. S causa que $P$ quiere $M$.

2. $P$ trata de conseguir $M$ hasta que $P$ consigue $M$ o hasta que $P$ se da por vencido.

Es decir, un episodio de resolución de problema es el que algo (S) le ocurre a alguien (P) que despierta en él un deseo por algo (M). La persona continúa intentando llegar a su meta hasta que fácilmente lo consigue o se da por vencida. Supóngașe que el esquema INTENTAR tiene la estructura interna siguiente:

INTENTAR (Persona $P$, meta M).

1. P decide sobre una acción $A$ que le podría llevar a $\mathrm{M}$.

2. Mientras que cualquier condición $A^{\prime}$ para que ocurra A no esté satisfecha, $P$ intenta conseguir A'.

3. P hace A.

Así pues, el esquema INTENTAR consiste en tres partes: decidir el plan apropiado de acción (A) realizar cualquier precondición (A') en ese plan de acción, finalmente llevar a cabo el plan en sí.

Consideremos ahora el modo en que estos esquemas pueden ayudarnos a comprender estas frases. Al presentársenos la primera frase (4a) el sistema de comprensión activa un número de esquemas basados en las claves superficiales de la frase (generalmente, los esquemas pueden también ser activados por medio de claves contextuales, que veremos más adelante). En este caso particular, por lo tanto, (María) y algo como (la llegada del heladero» deberá estar relacionado con variables del esquema OIR y similarmente se activará un esquema para el HELADERO que en su momento activará sus subesquemas, que en conjunto, constituyen nuestro conocimiento sobre heladeros. Estos incluirán el esquema VENDER con el (heladeron ya relacionado con la variable vendedor, y el (heladon relacio. nado con la variable que representa (productos). No obstante, las variables para comprador y dinero no tienen aún por qué estar rela: cionadas. Mientras tanto, ya que una de las cosas que sabemos sobre heladeros es que venden helados, el esquema HELADO se activa poniendo a nuestra disposición nuestro conocimiento sobre helados. Parte de este conocimiento es el hecho de que a mucha gente le gustan los helados. Esto nos hace esperar que encontraremos alguna de estas personas y la asignación de cualquiera de estos candida. tos a la variable GUSTADOR del esquema ahora activado, GUS- 
TAR. Llegados a este punto, algunas de las variables desconectadas en los esquemas GUSTAR y VENDER, pueden ser identificados mutuamente, ya que a uno le gusta normalmente lo que compra. El comprador, aún no relacionado, del esquema VENDER es un buen candidato para la primera variable del esquema GUSTAR, el gustador. De modo similar, HELADO, que une la variable productos con el esquema VENDER es un buen candidato para la segunda variable del esquema GUSTAR, el objeto gustado. Hasta aquí el único candidato para el comprador es María, siendo este el nombre de una per. sona, los requisitos para el comprador, en el esquema VENDER es. tán aparentemente satisfechos y se lleva a cabo una tentativa de asignar (María) a la variable comprador. En este punto hemos acti. vado, por lo menos, los esquemas HELADERO, VENDER, HELADO y GUSTAR. Ahora, una vez que disponemos del esquema GUSTAR se activa el esquema QUERER ya que, a menudo, queremos lo que nos gusta. Podemos así interpretar (4a) concluyendo que ya que los heladeros venden helados a los compradores y que a los compradores, normalmente les gusta lo que compran y que quieren lo que les gusta, y ya que María es un buen candidato como comprador, María probablemente quiere un helado.

Antes de seguir con el análisis deberían hacerse un par de ob. servaciones; aunque nos haya tomado, más o menos, uná página explicar la comprensión de una simple frase; nuestro informe no es todo lo detallado que desearíamos. Sin duda alguna, hemos hecho algunas suposiciones cuestionables y realizado algunos giros dudosos. No obstante, confiamos en que el mecanismo general por el que funcionan los esquemas, a fin de producir comprensión, haya quedado descrito adecuadamente. Por lo menos, debería quedar claro que el proceso es complejo. El resultado inmediato es un tipo de inferencia, pero no es, ni trata de ser, deductivamente válida. Más bien depende en gran medida de estereotipos, valores asignados por defecto a variables, y por eso es por lo que decimos cosas como (a uno le gusta normalmente lo que compra». Información de este tipo está incorporada en el esquema VENDER (y también en su simétrico, el esquema COMPRAR), pero su incorporación será como una asignación por defecto, determinada por la información distribucional de limitaciones de variable, a las que se ha aludido anteriormente. Dichas asignaciones tan sólo se hacen en ausencia de la información conflictiva. Se combina para dar interpretaciones probabilísticas de algunas oraciones que son consecuencias de otras y que son, por lo menos, inesperadas. De aquí, que si a la frase (4a) le siguiera la frase (5)

(5) Sacó su revólver y lo mató.

Sospechariamos que, en ausencia de indicaciones contextuales, 
es preciso un cierto grado de reinterpretación, para modificar algu. nos de los hallazgos de variable llevados a cabo en la frase (4a), como resultado de la consecuencia, frase (5).

Volviendo ahora a nuestro ejemplo, hemos llegado a la conclusión de que María probablemente desea un helado y es en este punto cuando invocamos nuestro esquema de resolución de proble. ma abstracto, pues los deseos forman a menudo parte de episodios de resolución de problemas. Consecuentemente, entre otros, el es. quema de resolución de problemas prefigurado anteriormente, va a ser activado. Este esquema requiere que un suceso de ser consciente de la llegada del heladero es causa suficiente. Así pues, la variable del suceso, $\mathrm{S}$ del esquema de resolución de problemas se relaciona. ría, con el suceso de que María oye al heladero, la variable $\mathrm{P}$ con (Maria), y la variable $\mathrm{M}$ con (helado». La segunda línea del esque. ma de resolución de problema nos dice que $\mathbf{P}$ trata de conseguir $\mathbf{M}$, podemos por lo tanto esperar encontrar evidencias de que María trate de conseguir el helado. Probablemente, incluso antes de que este proceso esté completado, ya habremos leído la frase siguiente (4b) sobre el dinero de María, y ahora tendremos una buena razón para tratar de interpretar esto como, por lo menos, relacionado con un intento por parte de María para conseguir el helado. Para llevar esto a cabo necesitamos utilizar nuestro esquema INTENTAR, que revela que el primer paso consiste en decidir nuestro plan de acción, que nos llevará a la culminación de la meta. Ahora ya tenemos un esquema apropiado disponible, en concreto, el que tiene a María como comprador del Helado del Heladero, (el esquema puesto en marcha VENDER). Esta elección es apoyada por la evidencia que nos proporciona la frase (4b), pues el comprador necesita dinero; María recuerda su dinero, luego probablemente decide comprar el helado. Ahora esperamos encontrar un input tanto para María comprando el helado, como para el tratar de satisfácer alguna precondi. - ción para hacerlo. Así pues; cuando en la frase (4c) vemos a María yendo a la casa, podemos concluir que trataba de obtener su dinero de la casa. Al hacer estas asociaciones y al no encontrar más estímulo, concluímos nuestro proceso con la interpretación esquematizada dada anteriormente. Esto es, hemos comprendido el retazo de la historia, componiendo una configuración de esquemas y sus uniones de variables, que parecen justificar todos los aspectos de ella, aunque no teníamos un único esquema que respondiera por el evento particular descrito.

El esquema abstracto utilizado para ilustrar la comprensión de las frases $(4 \mathrm{a})$-(4c) es realmente muy general. Pueden ser utilizados para cubrir muchos ejemplos de intentar y resolver problemas. Consideremos los siguientes ejemplos, algo más complejos, de Schank y Abelson (1975): 
6a Juan sabia que la operación de su esposa sería cara.

6b Siempre estaba tio Enrique...

6c Juan buscó el listín de teléfonos.

De nuevo, estas frases pueden ser fácilmente interpretadas utilizando los dos esquemas abstractos ya utilizados. El hecho de que Juan fuera consciente de que la operación de su esposa fuera cara, une la variable evento al esquema abstracto de resolución de pro. blema. Lo que hace que Juan quiera algo, en concreto, dinero, y por lo tanto intenta obtenerlo. Decide pedirlo prestado a su tio Enrique. Una condición de pedir prestado es preguntar, y preguntar requiere contactar. Una forma de contactar es por teléfono. Una guía de teléfonos se usa como parte de la acción de telefonear. Así pues, intenta telefonear al tío Enrique para pedirle dinero.

Si la comprensión se realiza realmente como hemos sugerido, se puede suponer que sería posible aducir una simulación del proce. so mediante un computador. De hecho conocemos casos en los que los detalles de la operación de un sistema tal, han sido adecuada. mente especificados para determinar si se puede o no alcanzar la comprensión. Schank et al (1975) desarrollaron un sistema computado llamado SAM, con el cual pueden aplicar esquemas a un nivel intermedio de abstracción, y uno de nosotros (DER), ha desarrollado un sistema computado denominado MUNDOHISTORIA, con el cual es posible aplicar versiones muy simples del esquema resolución de problema ya mencionado. Pero nadie ha desarrollado aún un siste. ma procesado mediante un computador, de sofisticación suficiente, ni un conocimiento base tan rico como para que podamos decir con certeza que estos mecanismos propuestos trabajarán al nivel que sugerimos.

\section{Esquemas y recuerdos}

Una exposición completa de la representación del conocimiento no puede restringirse solo al conocimiento genérico. No solo debe tratar lo que tradicionalmente se ha denominado memoria semántica, sino también lo que Tulving (1972) denominó memoria episódica. El contenido de la memoria episódica, conocimiento episódico.[véase Ortony (1975a)] es más específico, referido a esos recuerdos de eventos particulares experimentados directa o indirecta. mente. En,contraste el conocimiento genérico es el conocimiento que tenemos de conceptos, abstraidos de dichos recuerdos. En este apartado, tratamos la relación entre conocimiento episódico, recuerdos y teoría del esquema.

En cierto sentido nuestros recuerdos son efectos secundarios 
naturales del proceso de comprensión. En la comprensión varios as. pectos del estimulo están asociados con una configuración de esquemas, y estos esquemas puestos en marcha, constituyen nuestra interpretación del estímulo. Lo que se almacena en la memoria es, en efecto, una copia o una copia parcial de estos esquemas puestos en marcha, es decir, lo que se almacena no son estímulos en sí, sino la interpretación dada a ese estímulo como resultado del proceso de comprensión. De hecho estas huellas memorísticas no son probable. mente copias completas de los esquemas originalmente puestos en marcha, sino un grupo de fragmentos de ellos, mas o menos com. pleto. Tal vez, dicho almacenamiento parcial de información viene dado por lo incompleto del proceso de la copia original, debido a presiones de tiempo o a dificultades inherentes al proceso. Quizá varios aspectos de las huellas memorísticas se deterioran o se hacen inaccesibles con el tiempo. En cualquier caso, tras algún tiempo, sólo quedan fragmentos de las copias de los esquemas puestos en marcha originalmente y debemos utilizar estos fragmentos para tratar de reconstruir la interpretación original y por lo tanto (recordarm la situación de estímulo. Esta reconstrucción no es, sin embar. go, descarriada, sino que utiliza esquemas como ayuda para la inter. pretación de los fragmentos, del mismo modo que la comprensión utiliza los esquemas como ayuda en la interpretación de los estímulos sensoriales, hay pues un tipo de continuum entre la comprensión y el recuerdo; mientras que en el primero tenemos la imposición de una interpretación principalmente de (fragmentos sensoriales) en. trantes, en el segundo tenemos la imposición de una interpretación, principalmente, de (fragmentos de memoria). En ambos casos se utilizan los esquemas. Deberíamos subrayar que aunque pudieramos considerar el acto de recordar como el de percibir en su modalidad de memoria, los recuerdos episódicos, en los que habitualmente se basa, no son meros fragmentos del estímulo sensorial inicial, sino representaciones fragmentarias de nuestra interpretación de ese estimulo.

Tengamos en cuenta que el considerar así la memoria, produce dos fuentes de (importación" y de (distorsión) en nuestros recuer. dos, por una parte, el proceso inicial de comprensión implica un (re llenadon del esqueleto sensorial inicial -este rellenado permite inva. riablemente cierta libertad por parte del comprendedor-. Por otra parte, nuestra reconstrucción de la interpretación original puede muy bien llevarnos a imponer aụ́n una interpretación ligeramente distinta. Nos parece que el experimento aportado por Spiro (1975) brinda un apoyo a ambos tipos de procesos.

Habiendo ya sugerido una intima relación entre recordar y comprender, introduciremos ahora una conexión muy importante 
entre ambos procesos. En nuestra discusión sobre la comprensión, puede haber parecido que todo el proceso requería tan solo conocimiento genérico captado por los esquemas, pero esto no puede ser cierto, pues la interpretación de mundo exterior, muy frecuentemente, no sólo reclama la aportación de nuestro conocimiento genérico sino también de nuestros recuerdos específicos. Por ejemplo, cuando oímos una frase aunque parte de ella es nuevo y no exige referirse a los recuerdos (aunque por supuesto requiere la existencia de esquemas para saber comprender) otra parte de la frase se presupone como dada y puede perfectamente requerir referencias de los recuerdos almacenados (véase Clark [19.73], donde se discute la distinción entre dada-nueva en los estimulos lingüísticos). Así pues al unir variables, ciertas variables se unen a aspectos de la situación presen. te; otras variables se unen a aspectos de nuestros recuerdos de una situación relacionada. Presumiblemente es a través de dichas uniones que la nueva información se interrelaciona con la antigua de nuestros recuerdos, proporcionando asi la manera de que los recuerdos sobre determinados acontecimientos pasen a estar relacionados entre sí directamente. Finalmente el hecho de que nuestros re. cuerdos son representaciones de los estímulos interpretados y no de los estímulos en sí, tiene consecuencias-importantes para su recuperación. Ya que los esquemas particulares que serán activados a la hora de la comprensión no dependen solo del estímulo, sino también del contexto, distintos contextos pueden proporcionar distintos modelos de esquemas utilizables para la comprensión, aunque el estímulo sea el mismo. Una segunda presentación del estímulo (o parte de él) tenderá a ser de ayuda como clave para la recuperación, hasta el punto en que pueda ser interpretado de la misma forma que el original. En consecuencia los cambios en las condiciones contextuales que puedan prevalecer en el momento de la recuperación, comparados con aquellas condiciones que se dieron en el momento de presentación pueden llevar a un fallo para reconocer en la segunda presentación al mismo elemento que en la original. Por la misma ra. zón, fragmentos del original presentados como claves para la recuperación, pueden ser relativamente poco efectivos. De este modo la teoria del esquema explica los resultados de especificidad de codificación de Tulving y Thomson (1973) y otros.

\section{Inferencias con esquemas}

Hemos tratado el uso de los esquemas para la comprensión, al. macenamiento y recuperación de la información estímulo. Además de estas funciones los esquemas cumplen una importante función como poderosos dispositivos para establecer inferencias. 
Quizás, el modo más obvio de que los esquemas sirven para ha. cer inferencias, es como predictores de estimulos no observados. Al encontrar un esquema que explique una situación estímulo, podemos inferir aspectos probables de la situación que no hemos observado. Asi pues, si alguien nos cuenta que fue a un restaurante a cenar, podemos inferir que le dieron un menú, comunicó su elección al camarero y después pagó la comida. Podemos hacer tales inferen. cias porque el esquema RESTAURANTE tiene cosas como "cenando» (véase Shank y Abelson [1975] para la especificación de un esquema RESTAURANTE CENAR) como subesquemas. La activación de dichos subesquemas y sus constituyentes sirve de vehículo para dichas inferencias. Relacionado con éste, hay otro proceso inferencial que ya hemos tratado, en concreto, inferir la existencia del todo a partir de la observación de una parte. Por ejemplo, al ver un ojo, a menu: do podemos inferir la existencia de una cara. Esta inferencia está involucrada en el curso natural de la comprensión de un estímulo, y se produce por la activación de los esquemas dominantes, llevada a cabo por sus subesquemas. Un tercer tipo de inferencia ya tratado, supone el que se rellenen variables no especificadas. Las limitacio. nes de la variable, junto a nuestro conocimiento de casos particulares, nos permiten establecer buenas hipótesis acerca de las variables no especificadas, asignando valores ausentes típicos. Así, en nuestro ejemplo ROMPER, establecemos una hipótesis acerca del tipo de acción implicada en el rompimiento del globo, sin que de hecho, se nos haya dicho.

Además de este tipo de inferencias, que naturalmente ocurren durante la comprensión, los esquemas son de utilidad para lo que Collins Warnock, Aiello y Miller (1975) denominan razonamiento funcional. Consideremos la frase $7 \mathrm{~b}$ que responde a la cuestión $7 \mathrm{a}$, citada por Collins et al. como un ejemplo de razonamiento funcional:

7a cEs el Chaco la tierra del ganado vacuno? Sé que la tierra del ganado esta por allí abajo.

$7 \mathrm{~b}$ Creo que es más bien tierra de ganado lanar. Es como el oeste de Tejas, así que de algún modo me imagino que es tierra de gana. do vacuno.

Para explicar la frase $7 \mathrm{~b}$ podemos postular un esquema para (producción de bienes de granja) (una suposición razonable para los estudiantes de geografia). Prebablemente hay muchas variables climáticas como temperatura, precipitaciones y vegetación que determinan los productos agrícolas que pueden ser producidos. Puede darse una respuesta a la cuestión 7a si se supone que se fijan primero las variables climáticas del esquema, según su conexión con los valores que poseen respecto al Chaco. Se puede iniciar entonces una bús- 
queda de esquemas o recuerdos relacionados en los que las variables en cuestión tienen los mismos valores o parecidos. Si dicha bús. queda es fructuosa y revela un candidato se puede comprobar si (uganado vacuno") es un valor de su variable (productos agrícolas). En el caso de la frase $7 \mathrm{~b}$ la persona que responde, determina probablemente que ya que el oeste de Tejas es igual en valores de variables climáticas y que alli se cría ganado vacuno, se puede criar también ganado vacuno en el Chaco. Collins y sus colegas dan un número de ejemplos similares que ilustran el mismo proceso de razonamiento. Al parecer, una estrategia típica de razonamiento debe pues completar ciertas variables de un esquema y luego buscar casos que empa. rejen dichas variables y suponer que la variable no especificada posee el mismo valor que el ejemplo encontrado. Este es exactamente el mismo proceso que discutimos para completar variables no especificadas, consultando la memoria episódica. Aparentemente, este proceso puede ser aplicado como estrategia general de razonamiento.

El razonamiento funcional es un tipo de inferencia analógica. Los esquemas parecen tener parte importante en la explicitación del razonamiento analógico. Consideremos el siguiente problema analógico:

8 Neil Armstrong es a la Luna lo que Cristóbal Colón es a...

Un sistema basado en esquemas, tendría que encontrar en primer lugar un esquema puesto-en-marcha, o un recuerdo, en el que hubiera por lo menos dos variables, una unida por Neil Armstrong, otra unida por la Luna. Así, Cristóbal Colón podría ser sustituido por Neil Armstrong y sustituir la (Luna) por una variable libre X, y buscar en los recuerdos otro esquema puesto-en-marcha que se empareje con todas (o con casi todas) las demás variables (no valores). Llegados a este punto, se podría permitir como una respuesta el valor de la variable, $X$. En caso de que este procedimiento no lograra encontrar un ajuste, puede hallarse un nuevo esquema que relacione (Neil Armstrong) con (la Luna) y repetirse el proceso. Probablemente encontraríamos, por fin, que «Neil Armstrong» llevó a cabo una expedición exploratoria a la Luna y que Cristóbal Colón llevó a cabo una expedición exploratoria a América. Así, podría darse la respuesta (América).

Además de los procedimientos de inferencia concreta, como los descritos, existen también esquemas de razonamiento mucho más abstractos que nos permitirán llegar a conclusiones a partir de las premisas. En muchos casos, dichos esquemas serán afirmaciones generales de los tipos de reglas que se hallan frecuentemente en los li. bros de lógica. Al igual que otros esquemas, pueden contener variables que se conectan al utilizar los esquemas, y además, como otros 
esquemas, pueden variar en su nivel de abstracción. Así, al tiempo que existe probablemente un esquema de uso general, TRANSITIVIDAD, con complicadas limitaciones de variable, pueden también existir otros más específicos, en los que sea fija la variable relación. Asi, por ejemplo, si la variable relación en el esquema transitividad es fijada por una "causa física), obtendríamos el esquema de uso espe. cífico TRANSITIVIDAD CAUSAL que sigue:

\section{Transitividad causal (evento $E_{1}$ evento $E_{2}$ evento $E_{3}$ )}

1. Si E1 causa E2 y E2 causa E3, entonces ciertamente E1 causa E3

La utilización de tal esquema sería idéntica a la de los esquemas en general. Podría ser activado en los momentos apropiados (véase el apartado sobre principios de procesamiento, donde se trata más detalladamente la activación de los esquemas) y una vez activado se buscarán candidatos disponibles para conectar las variables. De este modo, las estrategias de razonamiento empleadas normalmente por la gente, pueden ser incorporadas fácilmente a una re. presentación esquemática del conocimiento como la que proponemos. Estos principios no solamente pueden incluir alas leyes del pen. samienton que se describen en los libros de texto sino también transcenderlas. Finalmente, y en un nivel mas general, es interesante notar que es posible considerar el proceso de comprensión total en la teoría de los esquemas, como si fuese un caso de razonamiento analógico. Cuando determinamos que una situación encaja en cier. to esquema, en cierto sentido estamos determinando que la situación presente es análoga a las situaciones de las que originalmente deriva el esquema. Por otra parte, cuando inferimos acerca de as. pectos no observados de las situaciones, estamos de hecho supo. niendo su existencia por analogía a partir de las situaciones a partir de las cuales se derivaron los esquemas.

\section{Los esquemas y la estructura de las acciones}

Al final del epigrafe dedicado a las características de los esquemas, indicábamos que los esquemas pueden también constituir el conocimiento subyacente utilizado para llevar a cabo las acciones. Examinemos más detalladamente esta idea ${ }^{3}$.

La mayor parte de la gente sabe pasar un objeto de una mano a otra. El problema que nos concierne es cómo representar ese conocimiento. ¿Cómo caracterizamos un esquema TRANSFERIR que organice y coordine el grupo de acciones implicadas? El esquema que sigue servirá a este propósito. Como todos los demás esquemas tiene variables y subesquemas: 
TRANSFERIR (objeto O desde la mano Mi hasta la mano Mf en el momento T)

1 LANZAR OMi a la posición Mf en T

2 COGER $\mathrm{O}$ con Mf en $\mathrm{T}+\delta \mathrm{T}$

$\mathrm{Mi}$, se toma como la mano inicial que sostiene el objeto $(\mathrm{O})$ al principio (tiempo T) y Mf es la mano con la que se sostiene finalmente el objeto como resultado de la transferencia. En este caso, TRANSFERIR se supone que posee cuatro variables y dos subesquemas encajados LANZAR Y COGER. LANZAR Y COGER son en sí esquemas complejos con variables y, a su vez, son representados por una configuración de subesquemas. Asi por ejemplo, COGER pue. de, grosso modo, tener la estructura interna siguiente:

COGER (objeto O mano M)

1 POSICION M en el PUNTO-DE-INTERCEPCION (de O con M)

2 Cuando $O$ contacta M AGARRA O con $M$

La invocación del esquema COGER, tendrá como resultado la activación de algo que podríamos denominar el esquema TRAYEC TORIA (por medio del esquema punto de intercepción). El esquema TRAYECTORIA permitirá a los valores de alguna de sus variables volver al esquema COGER. Este a su vez permitirá al esquema PO. SICION acercar la mano al punto de intercepción. La mejor manera de contemplar en último término, este fino sistema de sintonización que tiene lugar, será probablemente viéndolo como si estuviera bajo el control de un sistema de retro alimentación negativa, con re. ducción perceptible de la disparidad entre la posición de la mano y la posición del objeto (Petrie [9174] Powers [1973]).

Por supuesto el esquema TRANSFERIR puede ser utilizado como un constituyente de esquemas de acción más abstractos.

Consideremos por ejemplo el caso en el que tenemos un objeto en cada mano y queremos CAMBIAR los objetos lanzándolos de una mano a otra.

CAMBIO (objeto $\mathrm{O}_{1}$ con objeto $\mathrm{O}_{2}$ de mano $\mathrm{Mi}$ a mano $\mathrm{Mf}$ en el momento T).

1 TRANSFERIR (O, de $\mathrm{M}_{\mathrm{i}}$ a $\mathrm{M}_{\mathrm{f}}$ en T)

2 TRANSFERIR ( $\mathrm{O}_{2}$ de $\mathrm{M}_{\mathrm{f}}$ a $\mathrm{M}_{\mathrm{i}}$ al APICE (Oı)

El esquema APICE permite la determinación de una región en la que el objeto está en su punto más alto. Claramente deberá de re presentarse algún tipo de distribución de posiciones aunque la coordinación de transferencia no dependa de que un objeto esté exactamente en el punto más alto. El inicio del paso 2 en el esquema CAM. 
BIO podría así variar dentro de los límites. Un interesante rasgo del esquema APICE es su sútil mezcla de aspectos cognitivos y motores; implica comprensión o interpretación perceptual de estímulo y seguimiento perceptivo. Dudamos que pueda ser útil cualquier separación neta de los esquemas de acción y los que acabamos de tratar, como medio de interpretación de estímulos.

Directa o indirectamente, los esquemas de acción, aquí descri. tos, encuentran su lugar como subesquemas dentro de un esquema más complejo, en concreto el malabarismo por el método de cascada. Suponiendo que de los tres objetos, dos $\left(\mathrm{O}_{1}\right.$ y $\left.\mathrm{O}_{2}\right)$ parten de la mano derecha $\mathrm{Md}$, mientras que el tercero (O3) parte de la mano iz. quierda Mi. Tenemos el siguiente esquema MALABARISMO:

MALABARISMO (objeto $\mathrm{O}_{1}$ objeto $\mathrm{O}_{2}$ objeto $\mathrm{O}_{3}$ en tiempo $\mathrm{T}$ )

\section{CAMBIO ( $\mathrm{O}_{1}$ con $\mathrm{O}_{3}$ de $\mathrm{Md}$ a $\mathrm{Mi}$ en $\mathrm{T}$ ) \\ 2 MALABARISMO $\left(\mathrm{O}_{2} \mathrm{O}_{3} \mathrm{O}_{1}\right.$ en APICE [O 3$]$}

Hacer malabarismos, es pues representado repetitivamente, invócándose en primer lugar un CAMBIO de dos objetos y luego cuando el CAMBIO se ha realizado, invocándose de nuevo el esque. ma MALABARISMO, que a su vez inicia un nuevo CAMBIO etc.

Con estos ejemplos hemos tratado de mostrar que el conocimiento subyacente a la realización de acciones pueder ser representado del mismo modo que el conocimiento que subyace a la comprensión. Para clarificar la exposición, podemos distinguir entre esos dos tipos de conocimiento, como basados en esquemas de ac. ción y comprensión. Al mismo tiempo, podría enfatizarse que estos esquemas son casi siempre altamente interdependientes. La coordinación de muchas acciones requiere una interpretación de indicios perceptivos, a menudo seleccionados, a causa de que los esquemas de comprensión activados (buscan" con determinación variables relacionadas con la acción. Ya expusimos la interdependencia de los esquemas de acción y comprensión en el otro sentido, cuando nos ocupamos del esquema INTENTAR, cuyo constituyente es un esquema de acción.

Al parecer, los esquemas manejan la representación de acciones y secuencias de acción de forma natural, pues las características básicas de los esquemas se proyectan sobre algunas de las características cruciales de acciones. En primer lugar la existencia de variables en los esquemas de acción permite la flexibilidad requerida para la ejecución de las acciones. Así pues, cuando lanzamos una pelota de basket lo hacemos, probablemente, desde una posición en el suelo desde la cual nunca antes hemos lanzado. Sin embargo, estimamos distancia y ángulo (ambas variables en un esquema para lanzar pelo. 
ta de basket) y así determinamos la fuerza y la dirección en que debería de iniciarse al lanzamiento. En segundo lugar, el encaje de los esquemas de acción unos con otros, capta también algunas intuiciones importantes sobre las acciones, en concreto el hecho de que tienen estructuras constituyentes. Asi pues, aunque el hacer malabarismos es una acción única, tiene subacciones complejas como consti. tuyentes. Papert (comunicación personal) nos dice que la gente aprende a hacer malabarismos de forma más rápida si en primer lu. gar se dominan las subacciones que corresponden a nuestros esquemas a TRANSFERIR y CAMBIAR. Esto sugiere que estos subesquemas son constituyentes reales de hacer malabarismos, a pesar de la aparente unidad de las acciones de los malabaristas expertos. Finalmente, la existencia de los esquemas de acción en stodos los niveles de abstracción), nos permite explicar en principio las relaciones entre planes (esquemas de acción muy abstractos) y la ejecución de esos planes, incluso hasta el nivel de los menores movimientos de dedos.

\section{ADQUISICION Y MODIFICACION DE ESQUEMAS}

En la mayor parte de la exposición hecha hasta aquí, hemos to. mado los esquemas como algo dado, como herramientas cognitivas que existen ya en un principio. No hemos postulado mecanismos por medio de los cuales pueden aparecer nuevos esquemas y evolu. cionar los viejos. De hecho, este es un problema central de las teorías del esquema y se ha trabajado poco en él, sin embargo, la naturaleza de los esquemas sugiere un número plausible de mecanismos por los cuales se pueden producir nuevos esquemas. En este apartado nos centraremos en dos de estos mecanismos; especialización y generalización, ambos pueden ser considerados como tipos de aprendizaje.

\section{Especialización de los esquemas}

La especialización de los esquemas se da cuando una o más variables en un esquema son fijadas para formar un esquema menos abstracto. El esquema ROMPER, tratado anteriormente e ilustrado en la figura 2, nos servirá de ejemplo. Sería posible, por ejemplo, fijar la variable "objeton, $\mathrm{Y}$, como "globo».

Ya que, como se mencionó al hablar de las variables, las limita. ciones de variable interactúan, el fijar la variable objeto como (globois tendría repercusiones en las limitaciones asociadas con otras variables, como la variable método.

Así pues, el esquema original ROMPER podría especializarse 
en la producción de un nuevo esquema ROMPER GLOBO o ROMPER VENTANA etc. De forma similar el esquema abstracto de resolución de problema, que se utilizó en la interpretación sobre las fra. ses de María y el helado, frases de la $4 a$ a la 4c, podría especializarse en la producción de un esquema COMPRAR UN HELADO AL HE. LADERO. Obsérvese, que no hay limitaciones en la complejidad de nuestras descripciones de esquemas en el lenguaje corriente. Los conceptos representados por los esquemas no están restringidos a conceptos para los que existen elementos léxicos simples en la lengua.

El hecho de que la especialización de esquema pueda darse, no nos dice nada sobre las circunstancias bajo las que se da; probable. mente los criterios de especialización de esquema son frecuencia y utilidad. Si un esquema es utilizado frecuentemente, con los mismos valores asignados a algunas de sus variables, entonces puede generarse un esquema más especializado con esos valores fijados. Al mismo tiempo, algunos esquemas pueden ser tan generales que su utilización implica gran cantidad de trabajo, y deja mucha incertidum. bre respecto a la probabilidad de encaje de asignaciones ausentes. Ya que la especialización de esquema limita las asignaciones ausen. tes y reduce la cantidad de trabajo, su uso puede ser más efectivo. Así pues, en el ejemplo (helado), se requería mucho procesamiento para decidir el recurso al esquema de resolución de problemas, y de qué forma debieran unirse exactamente las variables dentro de los subesquemas.

Si construyéramos un esquema más específico, gran parte de este procesamiento podría ser evitado.

Consideremos otro ejemplo más extremo de la utilidad de este proceso de especialización, supongamos que tenemos un esquema para una cosa u objeto físico, supongamos entre sus variables su nombre y una lista de sus propiedades. Si resultara que un número significativo de esas propiedades se correlacionaran en gran medida con el nombre del concepto, seria muy útil la construcción de un esquẹma especializado para ese subgrupo de cosas que se asociarán a ese nombre particular. Podria ocurrir muy bien, que la existencia anterior de un número de dichos esquemas abstractos, unida a la maquinaria para la especialización de estos esquemas, fuera suficiente para explicar todos nuestros esquemas. Un ejemplo final del papel potencial de la especialización de esquemas en el aprendizaje, viene dado por el aprendizaje de habilidades motoras y la operación de los esquemas de acción. Consideramos lo que sucede cuando aprendemos a lanzar un dardo o un blanco. En un principio nos remitiremos a un esquema más bien general LANZAR, $y$ tratareos de determinar los valores correctos de las variables, para lanzar tipos 
particulares de dardo, desde distancias particulares. El esquema LANZAR es muy general, pero hay muchas variables por fijar y nuestra habilidad para fijarlas correctamente tal vez no sea grande. No obstante, una vez hemos lanzado un dardo concreto varias veces, nos familiarizamos con la determinación del ángulo correcto, la fuerza, etc., para lanzarlo. Así pues, téndría sentido el reunir estos valores en un esquema LANZAR DARDO, que podriamos invocar cuando quisiéramos lanzar dardos. El tremendo ahorro de esfuerzos en el reaprendizaje de actividades motoras confirmaría esta opinión.

Debería señalarse un último punto sobre la especialización, y este es la cuestión de procesos de almacenamiento/procesos de intercambio. Una de las virtudes de los esquemas relativamente generales es que pueden contribuir a la compresión de una serie de estí: mulos, los esquemas específicos, por otra parte, proporcionan una interpretación más rápida y más detallada de la gama de estímulos menores. Si permitimos que se generen demasiados esquemas especializados, puede ser que las diferencias entre ellos no sean lo suficientemente grandes, para permitirnos el aislamiento de los correctos. En consecuencia, el procesamiento que se ahorre en la comprensión puede derrocharse en la selección y poco se ganaría con esto; en general cuantas más estructuras hay en la memoria, mayores serán los requerimientos del almacenamiento y mayor el tiempo de procesamiento para la selección. Por esta razón la producción de esquemas especializados tiene que ser limitada a los casos en que pueda esperarse un resultado.

\section{Generalización del esquema}

La generalización del esquema es, por supuesto, lo contrario de la especialización. Esto es, una porción fija de un antiguo esquema es sustituida con una variable, para construir un esquema nuevo y más abstracto. Este modo de aprendizaje sería especialmente útil, cuando se nos presentara un caso en que ningún esquema satisfa. ciera exactamente una situación particular, pero un esquema se aproximará mucho a la situación difiriendo en un aspecto. Si esta situación se nos presenta repetidamente, podemos construir un nue. vo esquema similar al antiguo, pero en el cual la constante problemática ha sido sustituida por una variable. Las limitaciones de varia. ble para este nuevo esquema vendrían, probablemente, determinadas por la distribución de valores que nosotros observamos y que nos forzarán a crear esta nueva variable.

De nuevo lo ilustraremos con el esquema ROMPER de la figura 
2. Se puede determinar que el hecho de que un objeto sea rígido o frágil tan sólo presenta un subgrupo de casos particulares, y que el objeto debería de tener más características generales. Supongamos que un objeto estuviera limitado, de modo que, o.poseyera una es. tructura natural, o fuera normalmente utilizado para realizar cierta función. En este caso, la acción requerida sería distinta. Tendría que ser un tipo de acción capaz de destruir la estructura natural o de obs. truir la realización de la función del objeto. En tal caso se podría considerar el esquema ROMPER de la figura 2, como un caso particular del esquema ROMPER más general. La virtud del esquema más abstracto podría ser que con él, se manejarían otros casos de rompimiento, como en las frases 7 y 8 .

(7) Juan rompió la máquina de coser.

(8) Juan rompió su promesa.

En estos casos, nuestro esquema original ROMPER sería inadecuado, mucho más con respecto a la frase 8 , que con respecto a la frase 7. En el caso de la frase 7, tenemos cierta noción de destruir la función normal que suponemos en nuestro entendimiento, pues una máquina de coser rota es la que normalmente deja de funcio. nar como debiera, y no un montón de metal irreconocible, retorcido y físicamente mutilado. En el caso de la frase 8, una promesa puede ser considerada como una función social, la de proporcionar un cierto tipo de obligación o garantía. Los ejemplo 1, 2 y 3 también pueden ser manejados por un esquema más general. En el caso de las frases 1 y 2, ambas relacionadas con romper una ventana, puede considerarse que la función normal de la ventana ha sido obstruída. De hecho, se puede defender que la diferencia entre una ventana rota y otra agrietada está tan solo basada en este hecho. En el caso de la frase 3 la estructura natural, generalmente convexa, de un glo. bo es destruída. Todo lo que se necesitaría para la aplicación de un esquema más general sería el conocimiénto de la estructura natural, o las funciones normales en los esquemas que repreșentan los objetos en cuestión.

Si el esquema ROMPER más general, que acabamos de esquematizar, puede ser utilizado pàra explicar una gama más amplia de (crompimientos) que aquella de que era capaz el específico de la figura 2, se presenta de nuevo la cuestión de si necesitamos los dos y por qué. Dé nuevo la respuesta depende de si el esquema más especializado ROMPER, es de la suficiente utilidad, con la suficiente frecuencia, para ser almacenado como un esquema separado. Las dis. tinciones particulares dentro de los esquemas que posee un individuo, dependerán de la utilidad para ese individuo. Sería totalmente 
razonable esperar que un jugador de rugby tuviera un esquema de (romper un blocaje», aparte de su esquema ROMPER para propósitos con fines más conocimiento específico, y probablemente sería cho más conocimiento específico, y probablemente sería utilizado bastante a menudo.

El esquema DAR, que aparece en la figura 1 también puede ilustrar este punto. Si en su sentido más común la palabra dar implica el causar que algo cambie de posesión, cuando alguien (te da la lata) no parece que haya ningún objeto que cambie de posesión. Sin embargo, uno acaba poseyendo el objeto cuando alguien se lo da, parecería pues que el sentido de dar en (dar la lata) es un tipo de generalización de un esquema más específico, y probablemente anterior: esquema DAR. Así pues, los esquemas generalizados pueden también constituir un modo de interpretación de lo que Gentner (1975) denomina (extensiones metafóricas).

La importancia de la generalización de los esquemas para el aprendizaje es obvia. Los esquemas deben de ser generalizados, hasta el punto en que permitan la interpretación de los estímulos al sistema. Así pues se puede hacer frente a muchos aprendizajes, suponiendo que cuando un estímulo radicalmente nuevo se presente, se construirá un esquema sin variables, entonces cuando estímulos comparables se presentan lo suficientemente próximos al esquema original, se crea uno nuevo en el cual las diferencias pasan a ser variables, y las consecuencias lógicas se incorporan dentro de la estructura. Por el contrario, los esquemas más generales pueden adquirirse por medio del aprendizaje de, por ejemplo, principios generales y dichos esquemas pueden hacerse mas especializados, a medida que la gama de su aplicación se hace más y más aparente. Además de estas dos formas de formación de esquema, parece haber otro mecánismo de aprendizaje relacionado, natural para las teorías del esquema. Este está relacionado, pero no es idéntico con el mecanismo de generalización. Supongamos que se nos presenta una situación en la cual no podemos encontrar un esquema que explique la total configuración de los subesquemas que hemos descubierto. En este caso podemos almacenar nuestra interpretación parcial de la situación, un número de aspectos no relacionados. Si se nos presentan de nuevo configuraciones de esquemas muy similares, para los cuales no podamos aun encontrar un esquema total, podemos muy bien construir un nuevo esquema, cuya estructura interna se ajuste a los aspectos similares de las configuraciones, y cuyas variables se ajusten a la porción variable de estas situaciones. De este modo, podemos encontrar repetidamente configuraciones concurrentes de esquemas, y lograr así la especificación de un esquema nuevo y más abstracto. 
Antes de acabar con el cambio de esquemas, debería observar. se que parece razonable suponer, que no sólo pueden producirse es. quemas (por medio de los mecanismos que acabamos de esbozar), sino que también pueden evolucionar o (afinarse» los viejos esque. mas. En la teoria de esquemas, que hemos desarrollado aqui, hay tres formas por las cuales esto puede producirse, primero, podemos obtener más información precisa, sobre la naturaleza de las (distri. buciones) subyacentes a las limitaciones de variable. Cada vez que determinamos que un esquema en particular explique una situa. ción, podemos utilizar el valor de sus variables para modificar las limitaciones de variable y las correlaciones entre los diversos valores de variable. En segundo lugar podemos descartar aparentemente aspectos no relevantes de un esquema. Si una variable es raramente cubierta por la situación de estímulo, probablemente no es un aspec. to muy importante del esquema, y tal vez pueda ser descartado de la especificación del esquema. Un argumento similar podría aplicarse a las presumibles "propiedades fijas de un esquema). Si dichas propiedades nunca o raramente son observadas, no pueden constituir aspectos muy importantes del esquema. Finalmente, el viejo esque ma puede ser sintonizado por medio de la adición de nuevas varia. bles o propiedades fijas que le conciernen. Si un esquema dado difiere siempre de las situaciones a las que va dirigido en una pequeña diferencia constante, ese elemento constante debería de añadirse a la especificación del esquema.

Un caso real a este respecto es el de un chico de 5 años al que conocemos, que ahora cree que una sauna es cuna habitación de madera en la que muchos hombres estan sentados». Probablemente en un futuro no muy lejano este chico, con o sin influencias del mo. vimiento feminista, extenderá la limitación de los que utilizan la sauna a las mujeres, e introducirá varïables para los fines, y la tempera. tura, con un valor ausente comô (caliente).

Nuestra discusión sobre el aprendizaje ha sido necesariamente vaga. No obstante, parece ser que hay un número de mecanismos que pueden operar de forma natural dentro de la teoría del esque. ma, permitiendo el crecimiento natural y la evolución de un sistema de esquemas, que puede llevar a cabo las tareas para las que se le requiere.

\section{PRINCIPIOS DE PROCESAMIENTO}

Tradicionalmente se venía haciendo una neta distinción entre estructuras y procesos cognitivos. No obstante, más recientemente ha disminuído el énfasis dado a esta distinción, por dos razones que 
se relacionan. En primer lugar, se han desarrollado modelos en los cuales se ha representado al conocimiento procesualmente,(veáse Hewitt 1975, Winograd 1972). En segundo lugar, se han desarrolla. do modelos que representan a muchos procesos cognitivos, como estructuras idénticas en sus características a las utilizadas para representar el conocimiento más estático. Nuestra sugerencia para los es. quemas generales de resolución de problema, y de inferencia, son ejemplos de este desarrollo más reciente. Sin embargo, se da el caso de que se requieren principios de procesamiento más global para - explicar la disponibilidad de los conceptos correctos en el tiempo correcto. Una teoría de la representación del conocimiento no ha de ignorar este punto. A lo largo de este trabajo hemos utilizado repetidamente términos como (activáción) e (invocación) que han aflorado en los puntos clave de nuestra discusión, sobre la mayoría de los aspectos de la teoría. Por lo tanto, es necesario que los considere. mos más detalladamente.

Todo el sistema de memoria contiene gran número de esquemas y recuerdos. En un momento dado tan solo se requieren algunos, y ningún procedimiento de búsqueda al azar conduciría a su descubrimiento eficaz. La búsqueda de un probable esquema candidato debe, así, ser guiada de algun modo, y debe ser sensible al con. texto, pues las elecciones (correctas) dependen a menudo del con. texto en el que se da el proceso. El mismo estímulo es interpretado de forma distinta por un observador, dependiendo de las condiciones bajo las que lo observa, lo que acaba de observar, y lo que espera observar. Además, aunque las expectativas son obviamente im. portantes, los eventos no esperados pueden ser interpretados sin pasar primero por todas las interpretaciones posibles. Así pues, lo que al parecer se necesita es un proceso que permita la convergencia de la información, de modo que la información derivada directamente del estímulo, pueda combinarse con las expectativas, para que nos conduzcan (más o menos directamente) a un esquema candidato plausible.

Creemos que los esquemas tienen características que permiten satisfacer estos requisitos de forma rápida. Se llega a la convergencia por medio de la combinación de los procesamientos «de abajo arriba» $\mathrm{y}$ (de arriba abajo»: El procesamiento de abajo arriba se da, cuando los aspectos del estímulo sugieren o activan directamente los esquemas que les corresponden y cuando estos mismos esque. mas activan o sugieren esquemas dominantes de los que son constituyentes. En nuestro ejemplo de María y el heladero, -frases $4 \mathrm{a}-4 \mathrm{c}-$, la aparición de una palabra como (oórn (o una palabra afin) en el estímulo, activarían directamente el esquema OIR. El esquema OIR puede por sí mismo activar un esquema dominante, como chacerse 
consciente dem, y éste, al ser un evento, sugeriría el esquema de re. solución de problema. De un modo general, queremos decir, que los esquemas activados por sus propios constituyentes son activados de abajo a arriba, de modo que este procesamiento de abajo arriba, es la activación de los esquemas dominates. El procesamiento de arriba abajo, por otra parte, tiene su origen en que los esquemas activan sus subesquemas constituyentes. En nuestro ejemplo del helado, la activación del esquema VENDER por el esquema HELADERO es un claro ejemplo de esto, como lo es la activación del esquema IN. TENTAR por el esquema general de resolución de problema. Estos procesos se denominan (de arriba a abajon, porque nos conducen a partir de expectativas conceptuales, hacia los datos en el estímulo, donde pueden satisfacerse estas expectativas. De hecho, dicho procesos no necesitan volver al estímulo ya que pueden encontrarse con el proceso de abajo a arriba. Bobrow y Norman 1975 denominan a este ültimo tipo de proceso conducido conceptualmente, ya que son los conceptos los que en última instancia, generan una búsqueda de constituyentes particulares, que ellos sugieren. Por otra parte, lo constrastan con el proceso conducido por datos en el que los datos del estímulo son en última instancia los que generan sugerencias para conceptos particulares.

Puede ser útil considerar estos procesos, como si fueran una metáfora de la programación de una computadora, pues se puede considerar a un esquema como un tipo de procedimiento. Los proce. dimientos tienen subrutinas y puede considerarse la activación de un esquema como la invocación de un procedimiento. Las variables de un esquema son análogas, pues, a las variables de un procedimien. to, mientras que los subesquemas son análogos a las subrutinas, que pueden ser invocadas a partir de él. La activación de los subesquemas dentro de un esquema es como el llamamiento o la invocación de las subrutinas dentro de un procedimiento. Este es el caso para. digma del procesamiento llevado conceptualmente. Sin embargo, al contrario de las llamadas de procedimiento ordinario en las que la corriente de control va tan solo del procedimiento a la subrutina, la corriente de control en un sistema de esquemas actúa en ambos sentidos. Es como si un procedimiento dado, no sólo pudiera invo. car sus propias subrutinas (procesamiento llevado conceptualmente) sino también pudiera invocar esos procedimientos en los que el mis. mo, era un subrutina (procesamiento llevado por datos). Finalmente, se debe pensar que estos procedimientos operan simultáneamente.

Si la combinación del procesamiento conducido conceptual. mente y conducido por datos agotara el mecanismo de procesa. miento tendriamos en nuestras manos un grave problema, pues en dicho caso no habría al parecer forma de evitar el que cada esque. 
ma en la memoria se activara, al activarse uno de ellos. La solución a este problema está en la noción de (dar cuenta del estímulo» que fue tratado en el epígrafe sobre la comprensión. Durante el curso normal del procesamiento algunos esquemas se evidenciarán más que otros, y serán en general aquellos esquemas sugeridos a partir de un número de fuentes distintas. El procesamiento centrará su foco en éstos. (Hallar una buena evidencia) puede lograrse de diver. sas maneras. En primer lugar un esquema necesita encontrar buenas uniones para sus variables, así pues si se invoca el esquema DAR tendría que haber candidatos para quien da, el receptor, y lo que se da. En segundo lugar, un esquema debería hallar evidencias para sus subesquemas. Así pues en el esquema DAR debería haber evidencias que sugirieran que el receptor obtuvo realmente lo dado y quizá también que ésto nos ocurrió al azar. En tercer lugar, tendría que ser posible encontrar un esquema dominante, que hasta cierto punto nos ofrezca un buen ajuste. Los esquemas que no consiguen evidenciarse de este modo dejan de procesarse y son desactivados, de modo que los esquemas dominantes en los que se producen pue. den utilizar la información de falta de ajuste para la valoración de su propio buen ajuste. Los detalles del mecanismo de evaluación van mas allá del alcance de este trabajo, pero una formulación matemática detallada sobre ello puede hallarse en Rumelhart (1977. b). Mencionamos antes que los factores contextuales y situacionales influyen en la interpretación de los estímulos. Ya que los esquemas son estructuras que proporcionan interpretaciones de estímulos de toda modalidad, el modo más simple para comprender el mecanis. mo por el cual dichos factores afectan a la comprensión, es conside. rar que el estímulo incluye esos factores. Por ejemplo considérese que la frase (9) se oyera en dos situaciones distintas: un bar y la fiesta de cumpleaños de un niño.

\section{(9) Me gustaría beber algo}

En un bar, se ven y se oyen continuamente cosas relacionadas con bares y se prevee el que muchos esquemas relacionados con ba. res serán activados a menos que haya una inconsciencia total del entorno. Cuando (9) aparece en tal situación y activa el esquema BE. BER, las bebidas que pueden encontrarse dentro del esquema BAR serán sugeridas a partir de más fuentes de lo que lo serian en una fiesta infantil donde puede ser que actualmente no esten activas. Así pues en el contexto de un bar se esperaría que la cerveza y los licores se sugirieran más firmemente y se esperaría encontrar mas evi. dencias para estos que para la limonada o la leche, que probablemente prevalecerían en una fiesta infantil. Así pues, el pronunciar la frase (9) dará expectativas diferentes en situaciones distintas. Efectos 
de contexto más locales, como la influencia de lo inmediatamente anterior, se manejan exactamente de la misma manera. En resumen, la información (en la que se incluye el estímulo y el contexto) se introduce en el sistema y sugiere directamente ciertos candidatos posibles de esquemas que lo expliquen. Al mismo tiempo, a medida que el procesamiento llevado por datos está en marcha, los esque. mas postulados activan sus esquemas dominantes, los cuales a su vez buscan aspectos hasta ahora inesperados de la situación. Este procesamiento llevado conceptualmente permite que sean efectivas ${ }^{4}$ las limitaciones contextuales internas. Se dice que un esquema proporciona una buen explicación de (aspectos de) la situación estímulo cuando puede hallar una buena evidencia de sí mismo.

\section{CONCLUSIONES}

Afirmamos que la teoría del esquema nos proporciona tanto los conceptos como el vocabulario para teorizar sobre la organización del conocimiento. De hecho, el que prevalezcan los conceptos relacionados con los esquemas en este volumen confirma este he. cho. Al mismo tiempo no se puede negar que los términos que utilizamos deben ser limitados, para evitar que sean absorbidos en todo tipo de relaciones incompatibles. A este fin hemos tratado de carac. terizar los conceptos a los que corresponden con mayor detalle. No puede esperarse que una teoría del esquema describa la estructura y la maquinaria de la mente, pero como una parte de ello creemos que es prometedora.

La noción de esquemas, en lo referente a la variación de abs. tracciones, se relaciona de forma más bien directa con los descubrimientos de Meyer, de los que no solo se informa en este volumen sino también en Meyer (1975) y en Meyer y McConkie (1973). Las in. vestigaciones de Meyer indican que una característica objetiva, independiente de la estructura lógica de un párrafo en prosa, permite hacer predicciones bastante específicas sobre la recordabilidad rela. tiva de las distintas ideas que se dan en él. Particularmente, ideas elevadas, que son más dominantes en la estructura lógica, se recuer. dan mejor que los detalles particulares, y son mejor recordados si su orden de aparición en el párrafo es congruente con su prioridad en la estructura. Como la propia Meyer señala, estos descubrimientos tienden a apoyar las afirmaciones de Ausubel (1963) acerca de la importancia de tener una estructura superior a la que acoplar los detalles. Esto puede traducirse rápidamente a la teoría del esquema. De hecho, Rumelhart (1975) describe con cierto detalle la estructura que podríamos esperar encontrar con ciertos tipos de esquemas de CUENTO en concreto en los cuentos para niños con (moraleja). Ya 
que un esquema CUENTO puede ser considerado como un grupo parcialmente ordenado de normas reescritas, y ya que estas normas (la gramática del cuento) encarnan la (presumible) estructura lógica de un tipo de cuentos, con suposiciones mínimas, se concluiría que se requeriría menos procesamiento para ajustar un cuento a un es. quema, cuando el cuento se aproxime más a la estructura del esquema que cuando no se aproxime. Y si se considera la comprensión para encontrar dichos ajustes, se puede concluir que es fácil com. prender un cuento cuya estructura se corresponda de forma aproximada con la del esquema CUENTO. No es dificil el razonar desde una mejor comprensión a una mejor (memoria de lo esencial). Puede hacerse tanto sobre bases teóricas como empíricas. Un cuento es tan solo un caso especial de un pasaje en prosa y no hay razón para creer que los descubrimientos de Meyer no puedan darse en los cuentos infantiles.

Expresado en términos de esquema podríamos llegar a dos conclusiones. En primer lugar si se supone que la unión de variables dentro de un esquema se lleva a cabo más fácilmente de arriba abajo, entonces al proporcionar información de forma estructurada, aproximándose más a la estructura del esquema que será necesario para su interpretación, maximiza la probabilidad de que la interpretación será apropiada y minimiza el procesamínto requerido. En tal caso, cada parte sucesiva de información, del modo en que es asimilado, proporciona un apoyo adicional a que la interpretación sea apropiada y minimiza el procesamiento requerido. En tal caso, cada parte sucesiva de información, del modo en que es asimilada, proporciona un apoyo adicional a que la interpretación conseguida has. ta ahora sea realmente apropiada o (satisfactoria). En segundo lu. gar y por un razonamiento paralelo, se puede confiar en udesembalar) algún esquema usado que se recuerde y este desembalaje será más eficaz si se lleva a cabo de arriba abajo. En este caso, los principales aspectos estructurales aparecerían antes que los detalles, que son en sí menos predecibles y se vuelven más específicos.

Las implicaciones que las teorías del esquema o cualquier otra teoría sobre la organización del conocimiento tienen para la educación deben ser por el momento consideradas tan solo como potenciales.

En espera de modelos más detallados podemos, no obstante, señalar algunas consideraciones generales. Uno de los propósitos de la instrucción es ciertamente el de proporcionar el tipo de conocimiento que sea de utilidad a una persona para el procedimiento de nueva información y para enfrentarse a nuevas situaciones. Este fin puede ser considerado equivalente al de producir estructuras de co. nocimiento, en el que se pueda procesar y comprender nueva infor. 
mación. La provisión de nuevas estructuras de conocimiento que no tengan esta característica es pues tan inútil como la provisión de nueva información para la cual no pueda hallarse estructura interpretativa. El propósito de un esquema es el de una plantilla cognitiva, a la que puedan emparejarse nuevos estímulos y en función de la cual puedan ser comprendidos.

Así pues, el papel de los ejemplos en la instrucción puede ser considerado como que proporcionan casos individuales, en los que un esquema puede tener sus variables unidas; ejemplos bien escogidos explotarán dicho esquema mostrando la naturaleza y unión de valores que pueden tomar sus variables. La producción de nuevas estructuras de conocimientos y manifestaciones de la forma en la que pueden ser utilizadas puede ser considerado como uno de los fines principales de la instrucción. Ortony (1975 b) argumenta que la metáfora es un poderoso instrumento instruccional. En el contexto actual, se puede considerar a las metáforas como ayudas para selec. cionar un esquema viejo, que, con modificaciones relativamente pequeñas, puede utilizarse para la producción de uno nuevo.

Se puede pues utilizar un esquema (flujo de agua) como base de la producción de un esquema "corriente eléctrica). El primero puede incorporar conocimiento en lo que concierne a la unidireccionalidad del flujo; separando capacidad del conducto, etc. Todo lo cual podría tener sus analogías con un esquema ccorriente eléctrica). La buena instrucción haría más clara la metáfora de la electrici. dad en cables como agua en tuberías, especificando las variables que permanecen y las que desaparecen. Lo que lo hace una metáfora después de todo es que parte de la nueva información no se ajus. tará en el viejo esquema.

La producción, modificación y puesta en marcha de esquemas nos parece que caracteriza tanto el aprendizaje informal como la escolarización formal. Hay muchas formas en las que se pueden dar, que van desde el descubrimiento a través de los juegos, hasta la intuición a través de la instrucción. En todos los casos se utiliza y sé re. quiere el conocimiento existente para la adquisición de nuevos conocimientos. Dejamos lo que esto implica con respecto al recién nacido a la consideración de biólogos y filósofos.

\section{Agradecimientos}

El presente trabajo fue subvencionado en parte por el Instituto Nacional de Salud, por el Instituto Nacional de Educación y por la Fundación Sloan. 


\section{Kant dice:}

Ninguna imagen de triángulo se adecuaría jamás al concepto de triángulo en general. En efecto, la imagen no alcanzaria la universalidad conceptual que hace que el concepto sea válido en relación con todos los trián. gulos..... El esquema del triángulo..... significa una regla de síntesis de la imaginación...... El concepto de cpe. rrom, significa una regla conforme a la cual mi imaginación es capaz de dibujar la figura de un animal cuadrú. pedo en general, sin estar limitada, ni a una figura particular que me ofrezca la experiencia, ni a cualquier posible imagen que pueda representar in concreto.

\section{Y continúa:}

...la imagen es un producto de la capacidad empirica de la imaginación reproductiva; el esquema de los conceptos sensibles, como el de las figuras en el espacio, es un producto y un monograma, por asi decir. lo, de la facultad imaginativa pura a priori. Es mediante ésta y conforme a ella como son posibles las imá. genes, pero tales imágenes sólo deberán estar vinculadas al concepto por medio del esquema al que pertenecen. (1977a).

2 Este esquema de resolución de problema está tratado detalladamente en Rumelhart (1975) y en Rumelhart

${ }^{3}$ La aplicación de los esquemas a las acciones no es nueva. Bartlett (1932) sugirió que teníamos esquemas motores para actividades tales como jugar al tenis. Mas recientemente Schmidt (1975) ha propuesto una teoría del esquema sobre el aprendizaje de la habilidad motora que continúa desarrollando las nociones de Bartlett. Muchas de las ideas tratadas en este apartadóderivan de D. A. Norman, Ross Bott y otros miembros del grupo de investigación LNR de la Universidad de California, San Diego, durante una serie de encuientros cientificos a finales de 1975.

${ }^{4}$ Podriamos señalar que la unión de variables es resultado de cada uno o de ambos tipos de procesamiento. Un esquema puede buscar activamente un (aspecto de el) estimulo para unirlo con una de sus variables (conducida conceptualmente) y/o dicho estimulo puede requirir alguna variable a la que pueda unirse (conducida por los datos).

\section{Referencias}

ANDERSON, J. R. \& BOWER, G. Human associative memory Washington, D. C. Winston 1973.

ANDERSON, R. C. \& ORTONY, A. On putting apples into bottles - A problem of polysemy Cognitive Psy- chology, 1975, 7, 167-180.

AuSUBEL, D. P. The psychology of meaningful verbal learning: An introduction to school learning. Nueva York: Grune \& Stratton, 1963.

Barclay, J. R., Bransford, J. D., Franks, J. J., McCarrell., N. S. \& Nitsch, K. Comprehension and semantic flexibility. Journal of Verbal Learning and Verbal Behavior, 1974, 13, 471.481.

BAETLETT, F. C. Remembering. Cambridge, Inglaterra: Cambridge University Press, 1932.

Bobrow, D. G. \& Norman, D. A. Some principles of memory schemata. En D. G. Bobrow \& A. M. Collins (Eds.), Representation and understanding: Studies in cognitive science. Nueva York: Academic Press, 1975.

CHARNIAK. E. Toward a model of children's story comprehension. Tesis doctoral inédita. Massachusetts Institute of Technology, 1972.(MIT Artificial Inteligence Laboratory Tech. Rep. AI.TR, 266, 1972.)

CHARNIAK, E. Organization and inference in a frame-like system of common sense knowledge. En las actas de Theoretical issues in natural language processing: An interdisciplinary workshop. Cambridge, Mass.: Bolt, Beranek, \& Newman, Inc., 1975. Pp. 42.51.

Clark, H. H. Comprehension and the given-newcontract. Comunicación presentada en una conferencia sobre aThe role of grammar in interdisciplinary linguistic researchw University of Bielefeld, Bielefeld, Germany, diciembre 1973. 
Collins, A. M. \& Quillian, M. R. Retrieval time from semantic memory. Joumal of Verbal Learning and Verbal Behavior, 1969, 8, 240.247.

Collins, A. M. WARnock, E. H., Aiello, N., \& Miller, M. L. Reasoning from incomplete knowledge. En D. G. Bobrow \& A. M. Collins (Eds.), Representation and understanding: Studies in cognitive science. Nueva York: Academic Press, 1975.

Craik, F. I. M. \& LoCKhaRT, R. S. Levels of processing: A framework for memory research. Journal of Verbal Learning and Verbal Behavior, 1972, 11,671.684.

FILMORE, C. The case for case. En E. Bach \& R. I. Harms (Eds.), Universals in linguistic theory. Nueva York: Holt, Rinehart, \&c Winston, 1968.

GENTNER, D. Evidence for the psychological reality of semantic components: The verbs of possession. En D. A. Norman, D. E. Rumelhart, \& the LNR Research Group, Explorations in cognition. San Francisco: Freeman, 1975.

HALFF, H. M., ORTONY, A., \& ANDERSON, R. C. A context-sensitive representation of word meanings. Memory and Cognition, en prensa.

HEwITT, C. Stereotypes as an ACTOR approach towards solving the problem of procedural attachment in FRAME theories. En proceedings of Theoretical issues in natural language processing: An interdisciplinary workshop. Cambridge, Mass.: Bolt, Beranek, \& Newman, Inc., 1975.

Johnson, M. K., BRAnSFord, J. D. \& SOLOMON, S. K. Memory for tacit implications of sentences, Journal of Experimental Psychology, 1973, 98, 203-205.

KANT, E. Critique of pure reason (Ist ed. 1781, 2nd ed. 1787, translated by N. Kemp Smith). Londres: Macmillan, 1963.

KINTSCH, W. Notes on the structure of semantic memory. En E. Tulving \& W. Donaldson (Eds.), Organization of memory. Nueva York: Academic Press, 1972.

LABOV, W. The boundaries of words and their meanings. En C. J. Bailey \& R. Shuy (Eds.), New ways of analyzing in English Washington, D. C.: Georgetown University Press, 1973.

LAKOFF, G. Hedges: A study in meaning criteria and the logic of fuzzy concepts. Papers from the Eighth Regional Meeting. Chicago Linguistics Society. Chicago: University of Chicago Linguistics Department, 1972.

MEYER, B. J. F. The organization of prose and its effects on memory. Amsterdam: North.Holland Publ., 1975.

MEYER, B. J. F., \& MCCONKIE, G. W. What is recalled after hearing a passage? Journal of Educational Psychology, 1973, 65, 109.117.

MinSKy, M. A framework for representing knowledge. En P. H. Winston (Ed.), The psychology of compu-. ter vision. Nueva York: McGraw.Hill, 1975.

Nóman, D. A. Resources and schemas replace stages of processing. Comunicación presentada en el Sixteenth Annual Meeting, The Psychonomic Society, Denver, Colorado, noviembre 1975.

Norman, D. A., RumelharT, D. E. \& the LNR Research Group. Explorations in cognition. San FrancisCo: Freeman, 1975.

ORTONY, A. How episodic is semantic memory? En las actas de Theoretical issues in natural language processing: An interdisciplinary workshop. Cambridge, Mass: Bolt Beranek \&c Newman, Inc., 1975. (a)

ORTONy, A. Why metaphors are necessary and not just nice. Educational Theory, 1975, 25, 45.53. (b)

PALMER, S. E. Visual perception and world knowledge: Notes on a model of sensory cognitive interaction. En D. A. Norman, D. E. Rumelhart, \& the LNR Research Group, Explorations in cognition, San Francisco: Freeman, 1975.

PETRIE, H. G. Action, perception and education. Educational Theory, 1974, 24, 33.45.

POLANYI, M. Personal knowledge. Chicago: University of Chicago Press, 1958.

POLANYI, M. The tacit dimension. Nueva York: Doubleday, 1966.

POWERS, W. T. Behavior: The control of perception. Chicago: Aldine, 1973.

Quillfan, M. R. Semantic memory. En M. Minsky (Ed.), Semantic information processing. Cambridge, Mass.: M.I.T. Press, 1968.

RiPS, L. J., ShobEN, E. J., \& SMITH, E. E. Semantic distance and the verification of semantic relations. Journal of Verbal Learning and Verbal Behavior, 1973, 12, 1.20.

RosCH, E. H. On the internal structure of perceptual and semantic categories. En T. E. Moore (Ed.), Cognitive development and the acquisition of languiage. Nueva York: Academic Press, 1973.

Rumfihart, D. E. Notes on a schema for stories. En D. G. Bobrow \& A. M. Collins (Eds.), Representation and understanding: Studies in cognitive science. Nueva York: Academic Press, 1975.

RumelharT, D. E. Understanding and summarizing brief stories. En D. La Berge \& S. J. Samuels (Eds.), Basic processes in reading: Perception and comprehension. Hillsdale, N. J.: Lawrence Erlbaum Associates, 1977. (a) 
RUMELHART, D. E. Toward an interactive model of reading. En S. Dornic (Ed.), Attention and performan$c e, V$. Hillsdale, N. J.: Lawrence Erlbaum Associates, 1977. (b)

Rumelhart, D. E., \& LeVIN, J. A. A language comprehension system. En D. A. Norman, D. E. Rumelhart, \& the LNR Research Group, Explorations in cognition. San Francisco: Freeman, 1975.

RumelharT, D. E., Lindsay, P. H., \& Norman, D. A. A process model for long-term memory. En E. Tulving \& W. Donaldson (Eds.), Organization of memory. Nueva York: Academic Press, 1972.

SCHANK, R. C. Conceptual dependency: A theory of natural language understandings. Cognitive Psychology, 1972, 3, 552-631.

SChank, R. C. \& the YAle A. I. Project. SAM - A story understander (Res. Rep. 43). New Haven, Connecticut: Yale University, Department of Computer Science, agosto 1975.

SCHANK, R. C., \& ABELSON, R. P. Scripts, plans and knowledge. En Advance Papers of the Fourth International Joint Conference on Artificial inteligence. Tbilisi, Georgia, USSR, 1975, Pp. 151-157.

SCHMIDT, R. A. A schema theory of discrete motor skill learning. Psychological Review, 1975, 82, 225.260.

SPIRO, R. J. Inferential reconstruction in memory for connected discours (Tech. Rep. No. 2). Urbana, III.: Laboratory for Cognitive Studies in Education, University of Illinois, 1975.

Tulving, E. Episodic and semantic memory. En E. Tulving \& W. Donaldson (Eds.), Organization of memory. Nueva York: Academic Press, 1972.

Tulving, E., \& Thomson, D. M. Encoding specificity and retrieval processes in episodic memory. Psychological Review, 1973, 80, 352-373.

WALKER, J. H. Real-world variability, reasonableness judgments, and memory representatios for concepts. Journal of Verbal Learning and Verbal Behavior, 1975, 14, 241-252.

WINOGRAD, T. Understanding natural language. Edinburgh: Edinburgh University Press, 1972.

WiNOGRAD, T. Frame representations and the declarative procedural controversy. En D. G. Bobrow \& A. M. Collins (Eds.). Representatios and understanding: Studies in cognitive science. Nueva York: Aca. demic Press, 1975. 